\title{
The Online Distribution System of Inventory-Routing Problem with Simultaneous Deliveries and Returns Concerning $\mathrm{CO}_{2}$ Emission Cost
}

\author{
Gia-Shie Liu ${ }^{1, *}$ and Kuo-Ping Lin ${ }^{2,3}$ (D) \\ 1 Department of Information Management, Lunghwa University of Science and Technology, \\ Taoyuan 33306, Taiwan \\ 2 Department of Industrial Engineering and Enterprise Information, Tunghai University, \\ Taichung 40704, Taiwan; kplin@thu.edu.tw or kuo.ping.lin@tdtu.edu.vn \\ 3 Faculty of Finance and Banking, Ton Duc Thang University, Ho Chi Minh City 729000, Vietnam \\ * Correspondence: liugtw@yahoo.com.tw; Tel.: +816-2-8209-3211 (ext. 6328)
}

Received: 19 May 2020; Accepted: 15 June 2020; Published: 18 June 2020

\begin{abstract}
This study attempts to consider $\mathrm{CO}_{2}$ emission cost to propose an online distribution system of inventory-routing problem with simultaneous deliveries and returns $\left(\mathrm{IRPSDRCO}_{2}\right)$. The proposed IRPSDRCO ${ }_{2}$ mathematical models will be developed to find the total inventory routing cost, the $\mathrm{CO}_{2}$ emission cost, the optimal delivery routes, the economic order quantities, the optimal reordering points, the optimal service levels, the optimal common review interval, and the optimal maximum inventory levels for all retail stores delivered in these scheduled routes. The proposed IRPSDRCO 2 model further applies the savings method, the target insert heuristic method, the target exchange heuristic method, and the repeated target heuristic method to find the optimal solution and the related scheduled routing plan. The sensitivity analyses will be conducted for this proposed IRPSDRCO 2 model based on different parameters to provide very helpful decision-making information for a distribution system design. The performance of the proposed repeated target heuristic method is demonstrated to be better than most of four other combination methods regarding both the inventory routing cost and CPU running time. Consequently, it should be very helpful for logistics firms to design their distribution system by following the structure and the detailed procedure flow of the online distribution system developed by this study.
\end{abstract}

Keywords: inventory-routing problem with simultaneous deliveries and returns; $\mathrm{CO}_{2}$ emission cost; target insert heuristic method; target exchange heuristic method; repeated target heuristic method; online distribution system

\section{Introduction and Literature Review}

Professional logistics companies in Taiwan usually deliver general products from depot to all retail stores by considering the trade-off relationship between transportation cost and inventory cost, which comprise the greatest part of total logistics cost. One of the well-known academic topics typically discussed in this field is the Inventory Routing Problem (IRP) [1-9]. Most IRP studies often apply transportation cost, holding cost, and ordering cost to design the related distribution system, but few of them use safety cost and shortage cost to conduct the routing plan. Reference [4] considers inventory holding cost, safety cost, shortage cost, ordering cost, and transportation cost to develop a decision support system of a green inventory-routing problem. Specifically, publishing products such as newspapers, magazines, books, greeting cards, and catalogs have the characteristic of a high return percentage [10]. The inventory-related costs are raised remarkably due to the return of out-of-date publishing products. Evidently, accurate forecasting of the merchandise and handling 
sales of out-of-date merchandise are very crucial. Unfortunately, these publishing logistics firms rarely consider the cost derived from returning out-of-date products back to depot and determine the delivered quantity of products for each retail store and the related vehicle delivery routes based on their past experiences. Accordingly, it is more appropriate to apply the academic field of the inventory-routing problem with simultaneous deliveries and returns (IRPSDR) to design the related distribution system.

Global warming is regarded as one of the most difficult concerns of this century. Thus, $\mathrm{CO}_{2}$ emission is gradually turning into the main concern for the whole world. Global warming mainly comes from increasing $\mathrm{CO}_{2}$ emission density in the atmosphere. To prevent global warming from becoming worse, several countries and organizations are complying with 'green' principles stipulated by the Kyoto Protocol, which took effect in 2005. Globalization, with its increasing industrial outsourcing needs, has resulted in transportation becoming the most important part that has strengthened $\mathrm{CO}_{2}$ emissions over the last two decades. In December 12 of 2015, nearly 200 nations completed the "Paris agreement" draft, which aims to keep global temperatures from rising another $2^{\circ}$ Celsius until 2100 by eliminating greenhouse gas pollution. As a result, transportation operations play the major role of global warming, which leads to the latter dilatation of green logistics [11]. In Taiwan, transportation accounted close to $13.9 \%$ of the total $\mathrm{CO}_{2}$ emissions generated in 2011, of which $\mathrm{CO}_{2}$ emissions from road transport comprised approximately $94.7 \%[12,13]$. In the academic field, there are some IRP studies discussing Greenhouse Gas (GHG) emission consumptions $[4,11,14,15]$. For a green IRP problem, Reference [15] analyzed the interests of horizontal collaboration regarding perishability, $\mathrm{CO}_{2}$ emissions from transportation activities, and logistics costs in the Inventory Routing Problem with numerous suppliers and customers by establishing a decision support model that can announce these concerns. Due to the enhancing environmental regard from the whole world, this paper intends to help logistics firms methodologically and practically design their distribution systems to include the produced $\mathrm{CO}_{2}$ emission cost into the objective function of the IRPSDR model, which becomes the IRPSDRCO ${ }_{2}$ model.

The development of Internet of Things (IoT) makes it possible to acquire a variety of real-time information. Real-time traffic and vehicle information based on IoT and mobile technology contribute to great significance on the vehicle routing planning. To optimize the routing planning of in-vehicle navigation with the help of IoT technology would decrease peoples' travel cost, improve travel safety and satisfaction on the navigation system, and it would improve the city's traffic condition globally. The vehicle routing problem (VRP) has always been the critical problem of traffic and navigation systems. Scholars have completed many studies about this topic [16-22]. According to our observations, most of them conduct the offline scheduled planning of the vehicle routing problem without considering instantaneous traffic congestion, which will cause more arrival time and fuel consumption. However, the recent development of IoT technology and the Internet of the vehicle would change the situation completely. This study tries to integrate mobile device, the Internet of the vehicle, and Google Map to enhance a traditional VRP navigation system into the online module of an IRPSDRCO $\mathrm{O}_{2}$ related navigation system, which can also conduct the instantaneous routing plan to handle the real traffic situation and immediate customer's requests. The IRPSDPCO ${ }_{2}$ developed by this study will first conduct scheduled vehicle routing planning and inventory control policy, which determine the optimal delivery routes, optimum review interval for all retail stores, and the related maximum level of products for each retail store located in those proposed routes based on the minimal total inventory routing cost criterion. Second, the instantaneous routing planning to handle the real traffic situation and immediate customer's requests will be conducted with the help of an online in-vehicle navigation system.

This research employs specific Taiwan publishing logistics firm's operating data to discuss its distribution system design problem. This study focuses on some specific logistics firms with a main distribution center, which deals with the distribution operation of publishing merchandise for many retail stores. However, it is not enough to only conduct re-ordering point inventory control policy in 
our proposed IRPSDPCO ${ }_{2}$ model. The main reason is that it has some economic disadvantages that the reorder point inventory control method conducts precise control over the inventory level of each merchandise item. For instance, each merchandise item is possibly ordered at a different time table and perhaps each retail store is also delivered at a different time table. Therefore, there are missing joint ordering, buying, or transportation economies. Furthermore, it will cause a lot of administrative difficulties in which the reordering point method requires constant monitoring of the inventory levels. Alternatively, under periodic review control, inventory levels for multiple merchandise items and different retail stores can be reviewed at the same time so that may be ordered and delivered at the same time, which realizes purchasing, production, or transportation economies. Compared to most of the previous existing IRP models, only applying reordering point inventory control policy to their methodological development, we will apply both the reordering point inventory control method and the periodic review inventory control method in our proposed IRPSDRCO ${ }_{2}$ model. Consequently, the inventory routing problem discussed in this research can be classified as two categories of reordering point inventory routing problem with simultaneous deliveries and returns concerning $\mathrm{CO}_{2}$ emission cost (ROPIRPSDRCO $\mathrm{C}_{2}$ ) and periodic review inventory routing problem with simultaneous deliveries and returns concerning $\mathrm{CO}_{2}$ emission cost (PRIRPSDRCO ${ }_{2}$ ).

The IRPSDRCO $\mathrm{O}_{2}$ proposed in this study is similar to a typical IRP problem, which is surely an NP-hard problem, and is not easy to manipulate by exact mathematical programming methods or simple heuristic approaches. The mathematical programming method can reach the optimal solution, but can only deal with a small-scale problem $[6,7,15,18]$. On the contrary, the simple heuristic approaches are normally applied to handle the large-scale NP-hard problem, but is frequently dropped into the local optimal solution [2,3,5,9]. Reference [3] studied a maritime IRP with time windows for deliveries with uncertain disruptions. A Lagrangian heuristic algorithm is proposed for acquiring flexible solutions by introducing auxiliary soft constraints incorporated in the objective function with Lagrange multipliers. Accordingly, meta-heuristic approaches have been employed to handle this type of difficult problem more efficiently to approach the optimal solution $[1,7,8,21,23,24]$. Reference [7] addressed a pickup and delivery inventory routing problem within time windows for a producer to distribute products packed in returnable transport items to a set of customers. A mixed-integer linear program is developed and tested on small-scale instances and a cluster first-route second meta-heuristic is proposed to handle more realistic large-scale problems. For decades to come, scholars have shown that the Tabu search (TS) method can deal with NP-hard problems such as VRP very efficiently. References $[16,17,25]$ proposed a two-phase TS combined with the savings method [26] and a simple 2-opt procedure [27] for the solution of location and routing problem (LRP), which are significant improvements over heuristic methods comprising SAV1, SAV2, and CLUST algorithms from Reference [28]. For the location and inventory routing problem (LIRP), Reference [29] proposed a hybrid heuristic method merging TS and SA, which is much better than the heuristic method from Reference [30] and the SA method. Moreover, Reference [1] showed that the modified genetic algorithm (GA) surpasses two former heuristic approaches. Reference [23] conducted a predicting particle swarm optimization (PSO) algorithm to optimize the routing assignment problem. Reference [21] proved that the improved PSO algorithm performs well in solution accuracy, but the original PSO works better in computational time. Reference [8] presented the suggested Tabu heuristic method, which was better than the other two methods when considering the average profit. All above literatures clearly show that meta-heuristic methods such as TS, GA, SA, PSO, or the combination methods of meta-heuristic methods and simple heuristic approaches can achieve better performances in terms of VRP, LRP, and LIRP problems. Unfortunately, these meta-heuristic methods generally need plenty of computation time to near the optimal solution, and, therefore, are not appropriate to be applied in the online distribution system of IRPSDRCO ${ }_{2}$ developed in this study. Accordingly, this proposed IRPSDRCO ${ }_{2}$ mathematical model first conducts savings method to obtain the initial solution. Then, it conducts a target insert heuristic method, a target exchange heuristic method, and a repeated target 
heuristic method, which are further conducted to find the optimal solution and the related scheduled routing planning.

\section{Problem Statement and Mathematical Model Formulation}

\subsection{Problem Statement and the Proposed Online Distribution System}

This paper primarily discusses the distribution operation of merchandise handled by some specific Taiwan logistics firm. This studied Taiwan logistics firm has a single main distribution center, which is in charge of the distribution operation for more than 5000 convenience retail stores, and delivers once a day and gets back the main distribution center after completing all deliveries of these retail stores. The proposed IRPSDRCO 2 mathematical model will be developed to deal with the scheduled delivery of products to all retail stores and the return of out-of-date products back to the distribution center, but need to reduce the problem scope due to several research constraints. An online distribution system is further developed to integrate the mobile device, Internet of the vehicle, and Google Map to enhance an online IRPSDRCO ${ }_{2}$ related navigation system for the distribution center run by some specific logistics firm. The structure of our proposed online distribution system are shown in Figure 1.

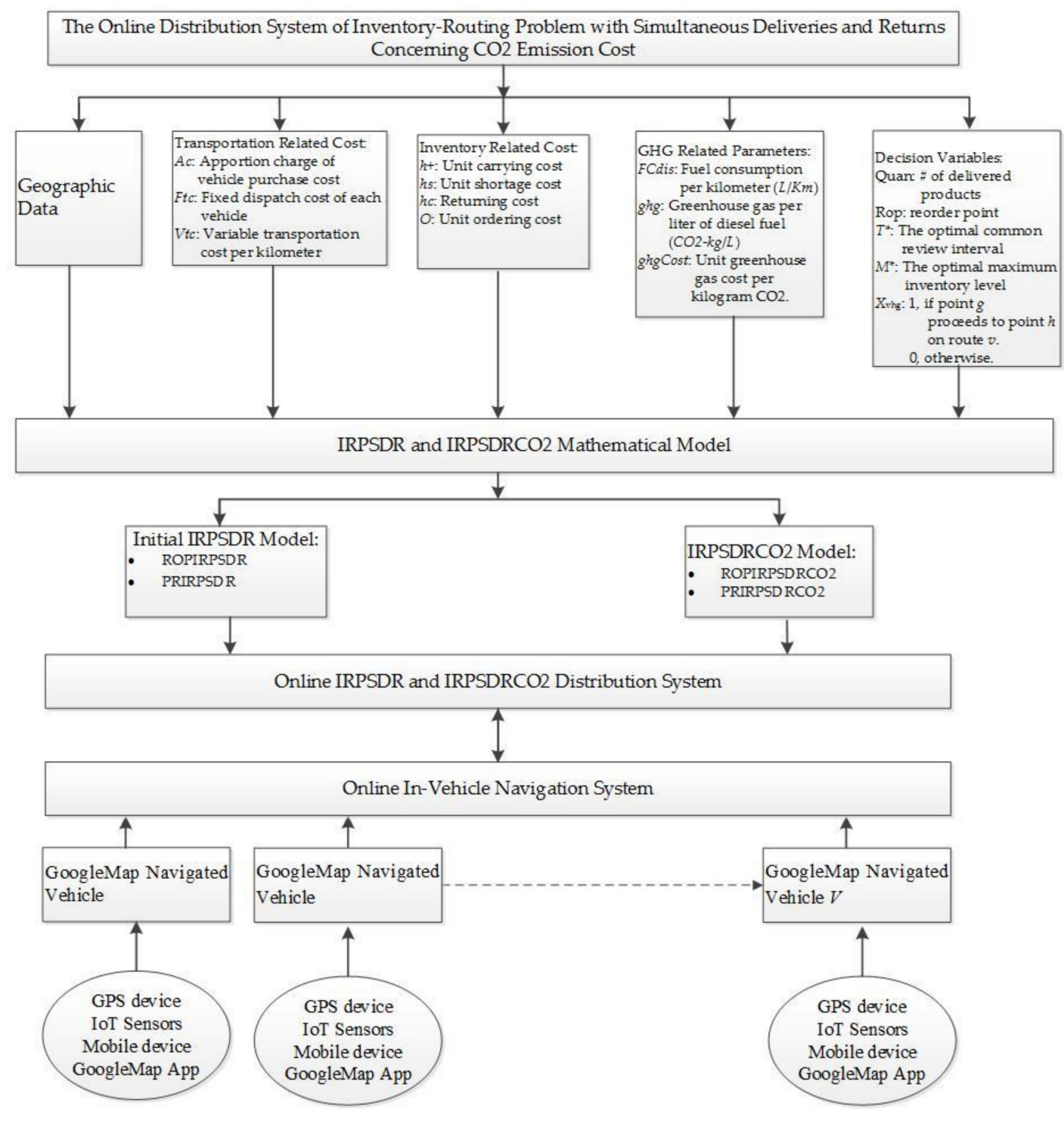

Figure 1. The structure of online IRPSDRCO $\mathrm{C}_{2}$ distribution system. 
The main structure of our proposed online distribution system shown in Figure 1 includes (1) IRPSDR and IRPSDRCO ${ }_{2}$ Mathematical Model, (2) online IRPSDR and IRPSDRCO ${ }_{2}$ distribution system, (3) Online In-Vehicle Navigation System, and (4) Google Map Navigated Vehicles Associated with GPS Devices, Mobile Devices, IoT Sensors, Google Map Apps.

\subsection{Research Limitations and Assumptions}

(1) This study considers a general publishing merchandise and single-depot inventory-routing problem with simultaneous deliveries and returns.

(2) The amount and location of the distribution center and retail stores are precisely acquired, and the actual distances of these stores are adopted in this study.

(3) The travel time between two retail stores is fixed and depends on the actual distance between these two stores.

(4) Each retail store is only delivered by one truck.

(5) Each route is also only delivered by one truck.

(6) All routes start and end at the same distribution center.

(7) The distribution center will not be restricted by the product capacity.

(8) The total demand of each route is less than or equal to the truck loading capacity.

(9) This research concerns ordering cost, inventory carrying cost, transportation cost, shortage cost, and returning cost of each store.

(10) The demand of each retail store is presumed to follow normal distribution or general distribution.

(11) The reordering inventory control policy and the period review inventory control policy are discussed.

(12) The types of all trucks are homogeneous Google Map navigated trucks associated with GPS devices, IoT sensors, mobile devices, and Google Map Apps.

(13) The proposed online in-vehicle navigation system sets up the route sequence planned by the IRPSDRCO ${ }_{2}$ model and adopts Google Map navigated trucks to navigate and conduct delivery and return operations.

\subsection{Notation}

$h, g, j:$ Index of retail stores and depot

$i$ : Index of retail stores

v: Index of vehicles

Decision variables:

Quan $_{v g h}$ : Volume of products delivered each time from store $g$ to store $h$ by truck $v$.

$R o p_{v g h}$ : The inventory level of reorder point for $h$ proceeded by $g$ on route $v$.

$T^{*}$ : The optimal common review interval for all retail stores.

$M_{i}^{*}$ : The optimal maximum inventory level for each retail store $i$.

$\mathrm{X}_{v g h}: 1$, if store $g$ immediately proceeds to store $h$ on route $v$ (truck $v$ ).

0 , otherwise.

$N$ : Amount of retail stores.

$V$ : Amount of vehicles.

cap: Limit of vehicle loading capacity.

Ac: Apportion charge of vehicle purchase cost.

Ftc: Fixed dispatch cost of each vehicle.

$V t c$ : Variable transportation cost per kilometer.

$h^{+}$: Unit carrying cost.

$h_{s}$ : Unit shortage cost. 
$h_{c}$ : Returning cost.

$O$ : Unit ordering cost.

FCdis: Fuel consumption per kilometer $(\mathrm{L} / \mathrm{Km})$.

$g h g$ : Greenhouse gas per liter of diesel fuel $(\mathrm{CO} 2-\mathrm{kg} / \mathrm{L})$.

ghgCost: Unit greenhouse gas cost per kilogram CO2. LT: Lead time.

$D_{e} m_{v g h}$ Total demand of products delivered within a period from store $g$ to $h$ by truck $v$.

$d_{e m} m_{v h}$ : Demand of products delivered each day from store $g$ to $h$ by truck $v$.

$L a d_{v g h}$ The average demand of store $h$ in route $v$ during the lead time.

$I n v_{v g h}$ The inventory level of store $h$ in route $v$ in which the replenishment order is placed.

$s_{d}$ : Standard deviation of product demand per day.

$s_{d}^{\prime}$ : Standard deviation of product demand within the lead time $\left(s_{d}^{\prime}=s_{d} \sqrt{L T}\right.$ for ROPIRPSDR and ROPIRPSDRCO2, $s_{d}^{\prime}=s_{d} \sqrt{L T+T^{*}}$ for PRIRPSDR and PRIRPSDRCO2).

$D_{i s_{v g h}}$ : Delivered distance from store $g$ to store $h$ by vehicle $v$.

$Y_{i j}: 1$ if retail store $j$ is assigned to distribution center $i, 0$ otherwise.

$u$ : One specific route in the proposed IRPSDRCO $\mathrm{I}_{2}$ distribution system.

$\bar{u}$ : All other routes in the proposed IRPSDRCO ${ }_{2}$ distribution system. $T$ _cost: Total inventory routing cost.

\subsection{Mathematical Model Formulation}

This study restricts the problem scope to one distribution center and around 5000 retail stores. The online IRPSDP and IRPSDPCO $\mathrm{O}_{2}$ mathematical models applying reordering point inventory policy (ROPIRPSDR and ROPIRPSDRCO $\mathrm{C}_{2}$ ) and period review inventory policy (PRIRPSDR and PRIRPSDRCO $\mathrm{O}_{2}$ ) are developed to find the optimal scheduled delivery routes, the economic order quantities, the optimal reordering points, the optimal service levels, the optimal common review interval, and the optimal maximum inventory levels for all retail stores delivered in these proposed routes. These two proposed mathematical models are delineated as follows.

Minimize the following:

Case 1: IRPSDR Model

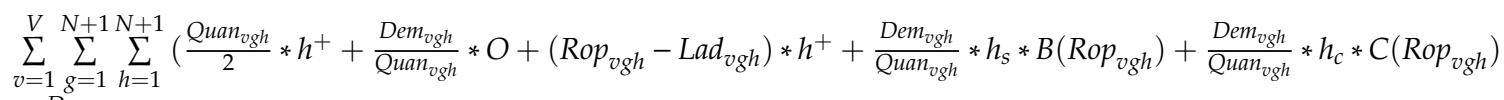

$$
\begin{aligned}
& \left.+\frac{\text { Dem }_{k g h}}{\operatorname{Quan}_{k g h}} *\left(V t c * D_{i s_{v g h}}+F t c\right)\right) * X_{v g h}+V * A c
\end{aligned}
$$

Case 2: IRPSDRCO 2 Model

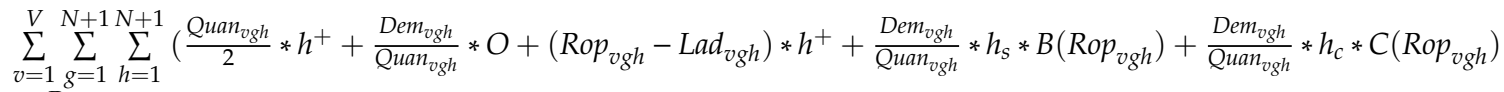

$$
\begin{aligned}
& \left.+\frac{\text { Dem }_{k g h}}{\text { Quan }_{k g h}} *\left(V t c * D_{i s} s_{v h}+F t c+F C d i s * g h g * D_{i s} s_{k h} * g h g C o s t\right)\right) * X_{v g h}+V * A c
\end{aligned}
$$

St: (both of Case 1 and Case 2)

$$
\begin{gathered}
\sum_{g=1}^{N+1} \sum_{h=1}^{N+1}\left(\text { Quan }_{v g h}+C\left(\text { ROP }_{v g h}\right)\right) \leq \text { cap }, \quad v=1, \cdots V \\
\sum_{v=1}^{V} \sum_{h=1}^{N+1} X_{g v h}=1, \quad g=1, \cdots N
\end{gathered}
$$




$$
\begin{gathered}
\sum_{g=1}^{N+1} X_{h g v}-\sum_{g=1}^{N+1} X_{g h v}=0, \quad v=1, \cdots V, h=1, \cdots N+1 \\
\sum_{g=1}^{N} \sum_{h=N+1}^{N+1} X_{g h v} \leq 1, v=1, \cdots V \\
\sum_{h=1}^{N+1} X_{i h v}+\sum_{h=1}^{N+1} X_{j h v}-Y_{i j} \leq 1, i=1, \cdots N, j=N+1, v=1, \cdots V \\
\sum_{g \in u} \sum_{h \in \bar{u}} \sum_{v=1}^{V} X_{g h k} \geq 1, \quad \forall(u, \bar{u}) \\
X_{v g h}=0, \quad 1, \quad g=1, \cdots N+1, h=1, \cdots N+1, \quad v=1, \cdots V \\
Y_{i j}=1, i=1, \cdots N, j=N+1
\end{gathered}
$$

In the above mathematical model formulation, the objective function includes the inventory routing costs of all retail stores located in all delivered routes.

\section{Case 1: IRPSDR Model}

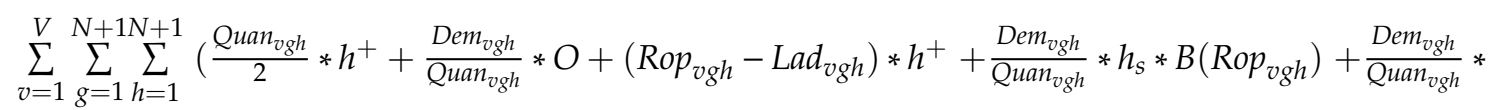

$\left.h_{c} * C\left(\operatorname{Rop}_{v g h}\right)+\frac{D e m_{v g h}}{\operatorname{Quan}_{v g h}} *\left(V t c * D i s_{v g h}+F t c\right)\right) * X_{v g h}$, and the apportion charge of fixed vehicle purchase cost $V * A c$.

The inventory-routing cost between two delivered retail stores can be described as follows:

$$
\begin{aligned}
& \frac{\text { Quan }_{\text {vgh }}}{2} * h^{+}+\frac{\text { Dem }_{\text {vgh }}}{\text { Quan }_{\text {vgh }}} * O+\left(\text { Rop }_{\text {vgh }}-L a a_{v g h}\right) * h^{+}+\frac{\text { Dem }_{\text {vgh }}}{\text { Quan }_{v g h}} * h_{S} * B\left(\operatorname{Rop}_{v g h}\right)
\end{aligned}
$$

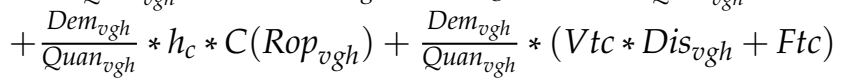

\section{Case 2: IRPSDRCO2 Model}

$$
\sum_{v=1}^{V} \sum_{g=1}^{N+1} \sum_{h=1}^{N+1}\left(\frac{\text { Quan }_{v g h}}{2} * h^{+}+\frac{\text { Dem }_{v g h}}{\text { Quan }_{v g h}} * O+\left(\text { Rop }_{v g h}-L a d_{v g h}\right) * h^{+}+\frac{\text { Dem }_{v g h}}{\text { Quan }_{v g h}} * h_{S} * B\left(\text { Rop }_{v g h}\right)+\frac{\text { Dem }_{v g h}}{\text { Ouan }_{v g h}} *\right.
$$

$\left.h_{c} * C\left(\operatorname{Rop}_{v g h}\right)+\frac{D e m_{v g h}}{\operatorname{Quan}_{v g h}} *\left(V t c * D i s_{v g h}+F t c\right)+\frac{D e m_{k g h}}{\operatorname{Quan}_{k g h}} *\left(F C d i s * g h g * D i s_{k g h} * g h g C o s t\right)\right) * X_{v g h}$, and the apportion charge of fixed vehicle purchase cost $V * A c$.

The inventory-routing cost between two delivered retail stores can be described as follows.

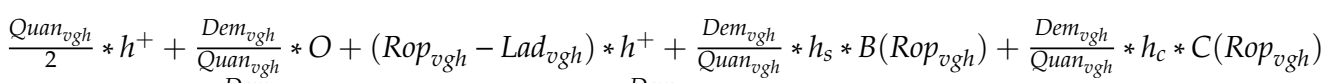

$$
\begin{aligned}
& +\frac{\text { Dem }_{v g h}}{\mathrm{Quan}_{v g h}} *\left(V t c * D i s_{v g h}+F t c\right)+\frac{\text { Dem }_{k g h}}{\mathrm{Quan}_{k g h}} *\left(F C d i s * g h g * D i s_{k g h} * g h g C o s t\right)
\end{aligned}
$$

The above cost includes the average inventory carrying cost, the ordering cost, the safety stock inventory carrying cost, the shortage cost, the returning cost, the transportation cost, and the greenhouse gas emission cost. They are described in detail as follows.

The average inventory carrying cost: $\left(\frac{\mathrm{Quan}_{v g h}}{2}\right) * h^{+}$

The ordering cost: $\frac{D e m_{\text {vgh }}}{\mathrm{Quan}_{\text {vgh }}} * O$

The safety stock inventory carrying cost: $\left(\operatorname{Rop}_{v g h}-L a d_{v g h}\right) * h^{+}$ 
The shortage cost: $\frac{\operatorname{Dem}_{v g h}}{\mathrm{Quan}_{v g h}} * h_{s} * B\left(\right.$ Rop $\left._{v g h}\right)$, where $B\left(\operatorname{Rop}_{v g h}\right)=\int_{\text {Rop }_{v g h}}^{\infty}\left(x-\operatorname{Rop}_{v g h}\right) f_{L}(x) d x$

The returning cost: $\frac{D e m_{v g h}}{Q u a n_{v g h}} * h_{c} * C\left(\right.$ Rop $\left._{v g h}\right)$, where $C\left(\right.$ Rop $\left._{v g h}\right)=\int_{0}^{R o p_{v g h}}\left(\operatorname{Rop}_{v g h}-x\right) f_{L}(x) d x$

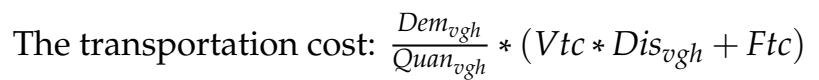

The greenhouse gas emission cost: $\frac{\operatorname{Dem}_{k g h}}{\mathrm{Quan}_{k g h}} *\left(F C d i s * g h g * D i s_{k g h} * g h g C o s t\right)$

In the above constraint functions, constraint (1) indicates that the quantity of each delivery to retail stores and the quantity of each return back to the distribution center must be less than or equal to vehicle loading capacity. Constraint (2) expresses that each customer can only appear in one route. Constraint (3) implies that each store entered by the truck should be the same store the truck leaves. Constraint (4) means a route can only be served by one distribution center. Constraint (5) denotes that a retail store can be assigned to a distribution center only if there is a route passing by that retail store. Constraint (6) states that each route begins and ends at the same distribution center. Constraints (7) and (8) represent the integrality of decision variables.

\subsection{The Procedure Flow of the Online IRPSDRCO $\mathrm{O}_{2}$ Distribution System}

The main procedure of our proposed online distribution system is as follows.

Step 1 Model Development: (1) Develop the simulated IRPSDR mathematical models including ROPIRPSDR, PRIRPSDR, ROPIRPSDRCO 2 , and PRIRPSDRCO . (2) Develop routing algorithms including a saving method, a target insert heuristic method, a target exchange heuristic method, and a repeated target heuristic method. (3) Develop the simulation cases regarding to different parameters including truck type, inventory carrying cost percentage, unit shortage cost, unit return cost, unit ordering cost, and unit transport cost. Step 2 Manipulation Process: (1) Input the relevant inventory routing information and $\mathrm{CO}_{2}$ information. (2) Obtain the Initial solution by conducting the saving method. (3) Improve the initial solution to approximate to the optimal solution by implementing the target insert heuristic method, target exchange heuristic method, and repeated target heuristic method. Step 3 Simulated Results Analysis: (1) Illustrate the simulated results including the optimum total inventory routing cost, the optimum scheduled delivery routes, and the economic order quantities, the optimum service levels, the reorder points, the optimum common review interval, and the optimum maximum inventory levels of all retail stores in these planned routes. (2) Conduct the sensitive analyses regarding different parameters including truck type, inventory carrying cost percentage, unit shortage cost, unit return cost, unit ordering cost, and unit transport cost. Step 4 Design the Delivered Routes: Visualizes and displays the planned online IRPSDR or IRPSDRCO $\mathrm{I}_{2}$ distribution system design. Step 5 Conduct the Delivery and Return Operation: Applies online in-vehicle navigation system to conduct the delivery and return operations according to the scheduled routes planned by the online IRPSDR or IRPSDRCO ${ }_{2}$ distribution system.

The detailed procedure flow of our proposed online distribution system are shown in Figure 2. 


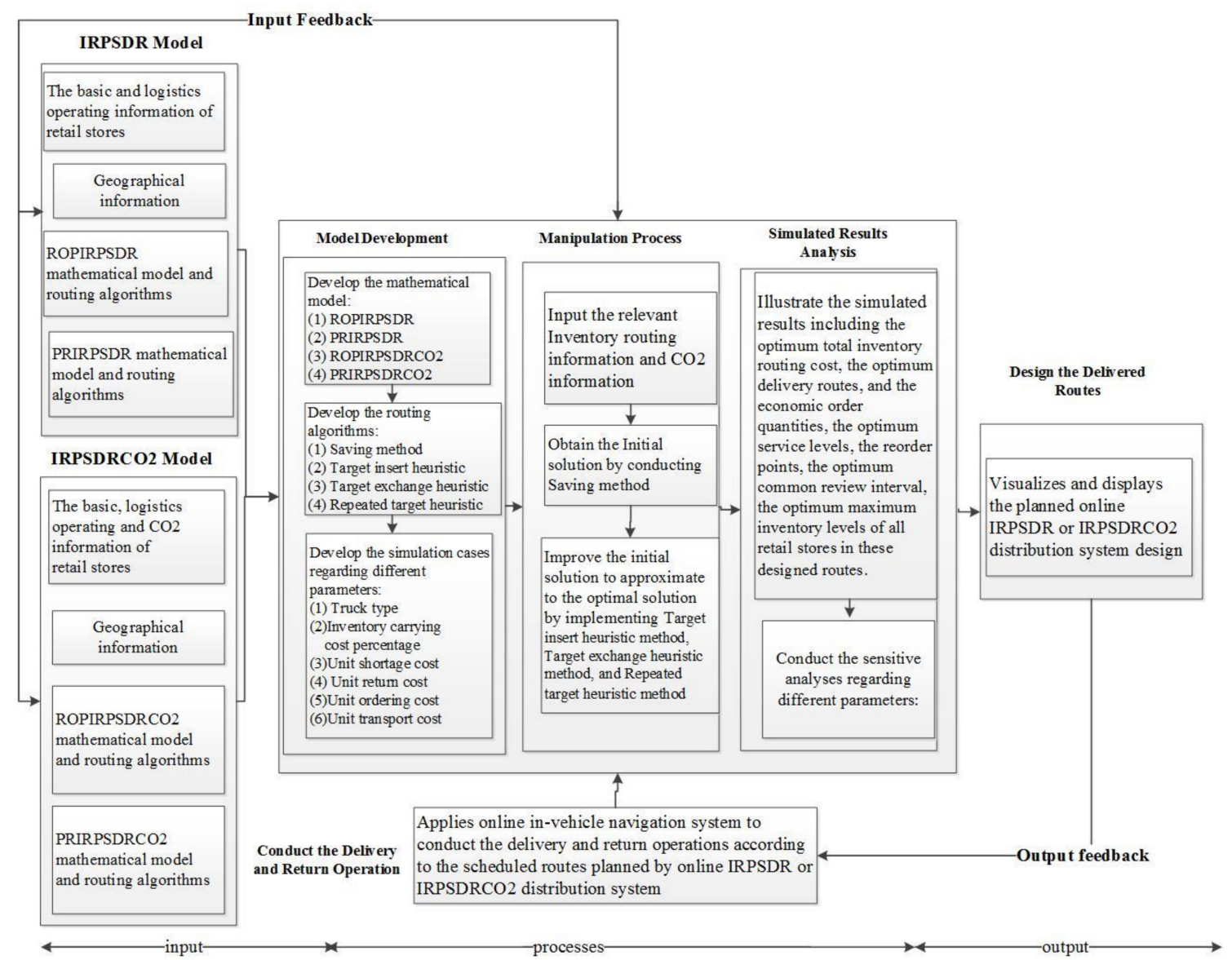

Figure 2. The procedure flow of online IRPSDRCO 2 distribution system.

\section{The Proposed Target Heuristic Methods}

This research applies the savings method [26] and three proposed target heuristic methods including the target insert heuristic method, the target exchange heuristic method, and the repeated target heuristic method are conducted to solve the proposed IRPSDRCO $\mathrm{O}_{2}$ model. First, in the first phase, the savings method is used to get the initial feasible solution. Moreover, in the second phase, the target insert heuristic method, target exchange heuristic method, and repeated target heuristic method are further conducted to find the optimal solution and the related scheduled routing planning. The detailed procedures of these proposed routing algorithms are delineated as follows.

Phase 1: Obtain the initial solution by conducting the savings method.

Step 1: Constitute the actual distances within all stores including one distribution center and all retail stores.

Step 2: Constitute the initial values of parameters including cap, Ac, Ftc, Vtc $, h^{+}, h_{s}, h_{c}, O, L T, D_{e m}$ kgh dem, $s_{d}$, FCdis, ghg, ghgCost .

Step 3: Conduct the savings method (from Step 4 to Step 9). The pair of retail stores with the largest savings value is picked to the route.

Step 4: Randomly choose one retail store $j 1$, and then select the next transit retail store to put in any position of the original route based on the total inventory routing cost, $T_{-}$cost. The calculation procedure of $T_{-}$cost is deducted in the following Step 5, Step 6, and Step 7.

Step 5: Compared to the VRP model, which adopts the actual distances within all stores including one distribution center and all retail stores to manipulate the optimal routing solution, our proposed IRPSDRCO $_{2}$ applies inventory routing cost within all stores to find the optimal solution instead. 
The procedure to obtain the optimal inventory routing cost within all stores is described in the following steps. The optimal economic order quantity $Q^{*}$, the optimal service level $P^{*}$, and the optimal reorder point $R o p^{*}$ for all retail stores can also be acquired simultaneously.

The reordering point inventory policy is applied in the following steps. The demand of all retail stores follow general distribution including normal distribution.

Step (1): Find the optimal delivered quantity and reorder point by first applying the reorder point inventory model.

The optimum delivered quantity and optimum reorder point can be obtained by presuming the first derivative of Equation (9) of case 1 and Equation (10) of case 2 equal to 0.

First, by presuming the first derivative of Equation (9) in Quan kgh $_{\text {equal }}$ to 0 for case 1 and the first

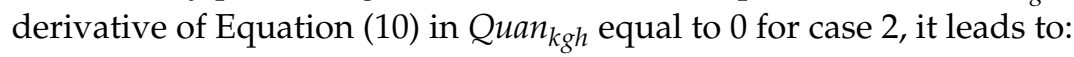

Case 1: IRPSDR Model

$$
\begin{gathered}
\frac{h^{+}}{2}-\frac{\operatorname{Dem}_{k g h}}{\operatorname{Quan}_{k g h}^{2}} * O-\frac{\operatorname{Dem}_{k g h}}{\operatorname{Quan}_{k g h}^{2}} * h_{s} * B\left(\operatorname{Rop}_{k g h}\right)-\frac{\operatorname{Dem}_{k g h}}{\operatorname{Quan}_{k g h}^{2}} * h_{c} * C\left(\operatorname{Rop}_{k g h}\right)-\frac{\operatorname{Dem}_{k g h}}{\operatorname{Quan} n_{k g h}^{2}} *\left(V t c * D i s_{k g h}+F t c\right)=0 \\
\Rightarrow \quad Q u a n_{k g h}^{*}=\sqrt{\frac{2 D e m_{k g h}\left(O+h_{s} * B\left(\operatorname{Rop}_{k g h}\right)+h_{c} * C\left(\operatorname{Rop}_{k g h}\right)+F t c+V t c * D i s_{k g h}\right)}{h^{+}}}
\end{gathered}
$$

\section{Case 2: IRPSDRCO 2 Model}

$$
\begin{aligned}
& \frac{h^{+}}{2}-\frac{\operatorname{Dem}_{k g h}}{\mathrm{Quan}_{k g h}^{2}} * O-\frac{\mathrm{Dem}_{k g h}}{\mathrm{Quan}_{k g h}^{2}} * h_{S} * B\left(\operatorname{Rop}_{k g h}\right)-\frac{\mathrm{Dem}_{k g h}}{\mathrm{Quan} n_{k g h}^{2}} * h_{c} * C\left(\operatorname{Rop}_{k g h}\right) \\
& -\frac{\text { Dem }_{k g h}}{\text { Quan }_{k g h}^{2}} *\left(V t c * D i s_{k g h}+F t c\right)-\frac{D^{2} m_{k g h}}{\text { Uuan }_{k g h}^{2}} *\left(F C d i s * g h g * D i s_{k g h} * g h g C o s t\right)=0 \\
& \Rightarrow \quad Q u a n_{k g h}^{*}=\sqrt{\frac{2 D e m_{k g h}\left(O+h_{s} * B\left(R_{o p} k_{g h}\right)+h_{c} * C\left(R o p_{k g h}\right)+F t c+V t c * D i i_{k g h}+F C d i s * g h{ }^{*} * D i_{k g h} * g h g \operatorname{Cost}\right)}{h^{+}}}
\end{aligned}
$$

By supposing the first derivative of Equation (9) in $\operatorname{Rop}_{\mathrm{kgh}}$ equal to 0 and the first derivative of Equation (10) in $R o p_{k g h}$ equal to 0 , it results in both case 1 and case 2 as follows.

$$
\begin{gathered}
h^{+}+h_{s} * \frac{D e m_{k g h}}{Q u a n_{k g h}} * \frac{d B\left(R o p_{k g h}\right)}{d R o p_{k g h}}+h_{c} * \frac{D e m_{k g h}}{Q u a n_{k g h}} * \frac{d C\left(R o p_{k g h}\right)}{d R o p_{k g h}}=0 \\
\Rightarrow \quad F_{L}\left(\operatorname{Rop}_{k g h}\right)=\frac{h_{s}}{h_{s}+h_{c}}-\frac{h^{+} Q_{k g h}}{\left(h_{s}+h_{c}\right) D_{k g h}}
\end{gathered}
$$

Step (2): Approximate the initial order quantity from the modified Economic Order Quantity (EOQ) formula.

Case 1: IRPSDR Model

$$
Q u a n_{k g h}=\sqrt{\frac{2 D e m *\left(\mathrm{O}+F t c+V t c * D i s_{k g h}\right)}{h^{+}}}
$$

Case 2: IRPSDRCO ${ }_{2}$ Model

$$
Q u a n_{k g h}=\sqrt{\frac{2 D e m *\left(O+F t c+V t c * D i s_{k g h}+F C d i s * g h g * D i s_{k g h} * g h g C o s t\right)}{h^{+}}}
$$

Step (3): Substitute Quan $k_{k g h}$ of (14) in case 1 or Quan $_{k g h}$ of (15) in case 2 into Equation (13) to obtain the revised $R o p_{k g h}$, respectively.

Step (4): Substitute the revised Rop $p_{k g h}$ obtained in Step (3) into Equation (11) in case 1 or Equation (12) in case 2 to find the revised Quan $k_{k g}$, respectively. 
Step (5): Substitute the revised Quan ${ }_{k g h}$ obtained in Step (4) into Equation (13) to determine the revised $R o p_{k g h}$.

Step (6): Repeat Step (4) and Step (5) until there is no more change in $R o p_{k g h}^{*}$ and $Q u a n_{k g h}^{*}$.

Step (7): Quan $_{v g h}^{*}$ of all retail stores given in Step (6) are applied to obtain the optimal common review interval for all retail stores.

$$
T^{*}=\frac{\sum_{i=1}^{N} \frac{\mathrm{Quan}_{i}^{*}}{\mathrm{dem}_{i}}}{N}
$$

Step (8): Apply Rop vgh of all retail stores given in Step (6) and $T^{*}$ given in Step (7) to find the optimum maximum inventory level for each store $i$.

$$
M_{i}^{*}=\operatorname{dem}_{\mathrm{i}}\left(T^{*}+L T\right)+\left(\operatorname{Rop}_{i}-\mathrm{Lad}_{i}\right)
$$

Step 6: Calculate service level $P_{k g h}^{*}=F_{L}\left(\right.$ Rop* $\left._{k g h}\right)$, and other statistics related to the above converged Rop $_{k g h}^{*}$ and Quan ${ }_{k g h}^{*}$.

Step 7: Acquire $T_{-} \operatorname{cost}(\mathrm{j} 1+\mathrm{j} 2)$ by inputting the final converged $P_{k g h^{\prime}}^{*} Q u a n_{k g h^{\prime}}^{*} R o p_{k g h^{\prime}}^{*}$ and the related statistics of all paired points to the following formula.

Case 1: IRPSDR Model

ROPIRPSDR mode:

$$
\begin{gathered}
\left(\frac{\text { Quan }_{k g h}^{*}}{2}\right) * h^{+}+\frac{\text { Dem }_{k g h}}{\operatorname{Quan}_{k g h}^{*}} * O+\left(\text { Rop }_{k g h}^{*}-\operatorname{Lad}_{k g h}\right) * h^{+}+\frac{D_{e m k g h}}{\operatorname{Quan}_{k g h}^{*}} * h_{s} * B\left(\operatorname{Rop}_{k g h}^{*}\right) \\
+\left(\frac{\text { Dem }_{v g h}}{\operatorname{Quan}_{v g h}} * h_{c} * C\left(\text { Rop }_{k g h}^{*}\right)+\frac{\text { Dem }_{k g h}}{\operatorname{Quan}_{k g h}^{*}} *\left(V t c * \operatorname{Dis}_{k g h}+F t c\right)\right.
\end{gathered}
$$

PRIRPSDR mode:

$$
\begin{aligned}
\left(\frac{\text { Quan }_{k g h}^{*}}{2}\right) * & h^{+}+\frac{\text { Dem }_{k g h}}{\operatorname{Quan}_{k g h}^{*}} * O+\left(\text { Rop }_{k g h}^{\prime}-\operatorname{Lad}_{k g h}\right) * h^{+}+\frac{D_{\text {emkgh }}}{\operatorname{Quan}_{k g h}^{*}} * h_{s} * B\left(\operatorname{Rop}_{k g h}^{\prime}\right) \\
& +\left(\frac{\text { Dem }_{v g h}}{\operatorname{Quan}_{v g h}} * h_{c} * C\left(\text { Rop }_{k g h}^{\prime}\right)+\frac{\text { Dem }_{k g h}}{\operatorname{Quan}_{k g h}^{*}} *\left(V t c * \operatorname{Dis}_{k g h}+F t c\right)\right.
\end{aligned}
$$

where $R O P^{\prime}=\operatorname{dem} *\left(L T+T^{*} / 2\right)+s_{d} * \sqrt{L T+T^{*}} * Z_{P^{*}}$

Case 2: IRPSDRCO ${ }_{2}$ Model

ROPIRPSDRCO $\mathrm{O}_{2}$ mode:

$$
\begin{aligned}
\left(\frac{\mathrm{Quan}_{k g h}^{*}}{2}\right) * h^{+}+ & \frac{\operatorname{Dem}_{k g h}}{\operatorname{Quan}_{k g h}^{*}} * O+\left(\operatorname{Rop}_{k g h}^{*}-\operatorname{Lad}_{k g h}\right) * h^{+}+\frac{D_{e m k g h}}{\operatorname{Quan}_{k g h}^{*}} * h_{s} * B\left(\operatorname{Rop}_{k g h}^{*}\right)+\left(\frac{\operatorname{Dem}_{v g h}}{\operatorname{Quan}_{v g h}} * h_{\mathcal{C}} * C\left(\operatorname{Rop}_{k g h}^{*}\right)\right. \\
& +\frac{\operatorname{Dem}_{k g h}}{\operatorname{Quan}_{k g h}^{*}} *\left(V t c * \operatorname{Dis}_{k g h}+F t c\right)+\frac{\operatorname{Dem}_{k g h}}{\operatorname{Quan}_{k g h}} *\left(F C d i s * g h g * \operatorname{Dis}_{k g h} * g h g \operatorname{Cos} t\right)
\end{aligned}
$$

PRIRPSDRCO2 mode:

$$
\begin{aligned}
\left(\frac{\operatorname{Quan}_{k g h}^{*}}{2}\right) * h^{+}+ & \frac{\operatorname{Dem}_{k g h}}{\operatorname{Quan}_{k g h}^{*}} * O+\left(\operatorname{Rop}_{k g h}^{\prime}-\operatorname{Lad}_{k g h}\right) * h^{+}+\frac{D_{e m k g h}}{\operatorname{Quan}_{k g h}^{*}} * h_{s} * B\left(\operatorname{Rop}_{k g h}^{\prime}\right)+\left(\frac{\text { Dem }_{v g h}}{\operatorname{Quan}_{v g h}} * h_{c} * C\left(\operatorname{Rop}_{k g h}^{\prime}\right)\right. \\
& +\frac{\operatorname{Dem}_{k g h}}{\operatorname{Quan}_{k g h}^{*}} *\left(V t c * \operatorname{Dis}_{k g h}+F t c\right)+\frac{\text { Dem }_{k g h}}{\operatorname{Quan}_{k g h}} *\left(F C d i s * g h g * \operatorname{Dis}_{k g h} * g h g \operatorname{Cos} t\right)
\end{aligned}
$$

where $R O P^{\prime}=\operatorname{dem} *\left(L T+T^{*} / 2\right)+s_{d} * \sqrt{L T+T^{*}} * Z_{P *}$ 
Calculate the difference value dif $=T_{\_} \operatorname{cost}(j 1+j 2)-T \_\operatorname{cost}(j 1)$ for all candidates of next transit retail stores. Choose the next transit retail store $j 2$ with the smallest difference value and check if total demand by adding $\mathrm{j} 2$ to the route, which, when the truck is loaded, is less than or equal to the truck loading capacity. If it is, retail store $j 2$ will be put into the route and marked. If it is not, reject $j 2$ and choose another retail store with the next smallest difference value to check it again. Repeat the above procedure until, eventually, you find the next transit retail store.

Step 8: Repeat Step 4, Step 5, Step 6, and Step 7 to choose the retail stores yet marked to be included in the route until the loading capacity of the truck delivered for the route is full.

Step 9: If there are still retail stores unselected, go back to Step 3. If not, directly proceed to Step 10.

Step 10: Record the current optimal solution including delivery routes, the objective function value, and the related decision variables to be the initial solution of phase 2 .

Step 11: Stop.

Phase 2: Improve the initial solution

After acquiring the initial total inventory routing cost in phase 1, we first conduct the target insert heuristic method to improve the initial total inventory routing cost. Next, the target exchange heuristic method is applied to ameliorate the current best total inventory routing cost. Lastly, we continue to advance the current best $T_{-}$cost by conducting the repeated target heuristic method, which duplicates the target insert heuristic method and target exchange heuristic method alternatively until no further improvement of $T_{\text {_cost }}$ has been done. The detailed procedures of the target insert heuristic method, target exchange heuristic method, and repeated target heuristic method in phase 2 are described as follows.

Target insert heuristic method:

Step 1: Set up the solution obtained in Phase 1 to be the initial solution of Phase 2.

Step 2: Assign the last route planned in Phase 1 as the target insert route to implement the target insert heuristic method.

Step 3: Calculate the objective function value by inserting all points located in all other routes into all possible positions between two points in the target route and check if it is possible to improve the initial solution obtained in phase 1 under the situation that the total amounts of delivered products of all retail stores originally in the target insert route plus the new inserted point from other routes is less than or equal to truck loading capacity. If yes, proceed to step 4 . Otherwise, proceed to step 5.

Step 4: Record all improved insert moves as the candidate list. Choose the insert move with the lowest objective function value from the candidate list and update the planned routes to deliver products to retail stores and return products to the distribution center. Return to step 3.

Step 5: Stop.

Target exchange heuristic method

Step 1: Set up the solution obtained from the target insert heuristic method to be the initial solution of the target exchange heuristic method.

Step 2: Appoint the last route planned by the target insert heuristic method as the target exchange route to run the target exchange heuristic method.

Step 3: Calculate the objective function value by exchanging all points located in all other routes with all possible points located in the target route and check if it is possible to improve the objective function solution obtained by the target insert heuristic method under the situation that the total amount of delivered products of all retail stores in the target exchange route and the total amount of delivered products of all retail stores in the selected exchange route are less than or equal to vehicle loading capacity. If yes, go to step 4. Otherwise, go to step 5 . 
Step 4: Record all improved exchange moves as the candidate list. Choose the exchange move with the lowest objective function value from the candidate list and update the planned routes to deliver products to retail stores and return products to the depot. Return to step 3.

Step 5: Stop.

Repeated target heuristic method:

Step 1: Set up Ite to be the number of iterations of non-improved target moves. Set up Max_Ite to be the defined threshold of iteration of non-improving target moves.

Step 2: Conduct the target insert heuristic method and target exchange heuristic method alternatively to improve the current lowest objective function value.

Step 3: If the objective function value is improved, go back to step 2, or set up Ite $=$ Ite +1 . Go to step 4 . Step 4: If Ite <= Max_Ite, go back step 2, or go to step 5.

Step 5: Stop.

\section{Simulated Numerical Results and Comparisons}

In the following simulation study cases, the targeted publishing logistics firm has only one distribution center, which ships different merchandise to no less than 5000 convenience retail stores once a day. Due to the complexity of real logistics operation realized by this distribution center, the problem will be too complicated to study if the complete procedure of a real operation is directly adopted to demonstrate these proposed target heuristic methods. This research picked all delivered convenience stores of 10 routes located at the high-density region of population plus the distribution depot to be the research targeted area. The complete manipulating data and parameters are given based on the typical operating activities of this simulation case.

(1) The average values and standard deviations of all 418 convenience stores are calculated based on the actual demands of the retail stores gathered by this study.

(2) The lead time is estimated to be one day.

(3) The price per unit of general merchandise is estimated to be 98 NT dollars.

(4) The carrying cost is presumed to be $20 \%$ of the merchandise's price.

(5) The ordering cost is assumed to be $100 \mathrm{NT}$ dollars per order.

(6) $h_{s}$ equals 20 NT dollars.

(7) $h_{c}$ equals 5 NT dollars.

(8) The 3.5-ton truck loading capacity is supposed to be around 3000 units of general merchandise, 7.8-ton truck loading capacity is around 6686 units of general merchandise, and an 11-ton truck loading capacity is around 9429 units of general merchandise.

(9) Apportion charge of fixed truck purchase cost $A c$ is predicted to be around 16,659 NT dollars by allocating the truck purchase cost to a 3-month period,

(10) Ftcs equals 30 NT dollars by allocating driver's salary to each retail store of the proposed delivered route.

(11) Vtc equals 3.9 NT dollars according to the average diesel fuel consumption.

(12) Greenhouse gas emission parameters for various truck types are described in Table 1.

Table 1. Greenhouse gas emission parameters for various vehicle types.

\begin{tabular}{cccccc}
\hline Vehicle Type & Fuel Consumption $(\mathbf{K m} / \mathbf{L})$ & $\mathbf{L} / \mathbf{K m}$ & $\mathbf{C O 2 - K g} / \mathbf{L}$ & $\mathbf{C O 2 - k g / K m}$ & $\mathbf{C O 2 - K g}$ \\
\hline & $(1)$ & $(2)=1 /(1)$ & $(3)$ & $(4)=(2) *(3)$ & $(4) *$ distance \\
3.5-ton truck & 8.12 & 0.12315 & 2.73 & 0.3362 & $0.3362 *$ distance \\
7.8-ton truck & 7.24 & 0.1381 & 2.73 & 0.3770 & $0.3770 *$ distance \\
11-ton truck & 6 & 0.1667 & 2.73 & 0.4551 & 0.4551 *distance \\
\hline
\end{tabular}




\subsection{The Simulated Results for the IRPSDR Model}

In this proposed simulation case, the IRPSDR model with the ROP mode (ROPIRPSDR) will be applied in the first replenishment run to deliver products to all retail stores. For the remaining replenishment runs, the IRPSDR model with a PR mode (PRIRPSDR) will be conducted to deliver products to all retail stores.

First, the total inventory routing costs for the proposed IRPSDR model with the ROP mode based on the above default operating data and parameters by conducting the savings method, target insert heuristic method, target exchange heuristic method, and repeated target heuristic method are illustrated in Table 2.

Table 2. The simulated numerical results for ROPIRPSDR.

\begin{tabular}{ccccc}
\hline Savings & $\begin{array}{c}\text { Target Insert } \\
\text { Heuristic }\end{array}$ & $\begin{array}{c}\text { Target Exchange } \\
\text { Heuristic }\end{array}$ & $\begin{array}{c}\text { Repeated } \\
\text { Target }\end{array}$ \\
\hline Number of routes & 8 & 8 & 8 & 8 \\
Inventory cost & $1,558,573$ & $1,523,036$ & $1,518,953$ & $1,475,353$ \\
Shortage cost & 368,177 & 361,901 & 361,078 & 351,742 \\
Return cost & 458,226 & 451,138 & 450,155 & 438,815 \\
Safety cost & 114,293 & 112,233 & 111,967 & 109,011 \\
Transport cost & 221,521 & 203,902 & 202,768 & 193,692 \\
Order cost & 524,773 & 516,362 & 515,220 & 502,120 \\
Total cost & $3,245,563$ & $3,168,572$ & $3,160,141$ & $3,070,733$ \\
Total cost saving & $0 \%$ & $2.37 \%$ & $2.63 \%$ & $5.69 \%$ \\
\hline
\end{tabular}

According to Table 2, the lowest total inventory routing cost 3,070,733 NT dollars is acquired by the proposed repeated target heuristic method. Since the lowest total inventory routing cost comes from the IRPSDR model with an ROP mode by implementing the proposed method, it can then decide the optimum delivery routes, economic order quantities, the optimum service levels, and the reorder points of all retail stores placed in these planed routes. From the point of view of decision making on this proposed inventory routing problem, the above result means that the decision makers should first deliver all products through eight planned optimal delivery routes to all retail stores, which conduct the related reordering inventory control policies. Table 3 shows the detailed route sequence for the first and last route of the eight delivery routes.

Table 3. The route order for retail stores delivered in Route 1, 8, based on ROPIRPSDR.

\begin{tabular}{c}
\hline Route 1 \\
\hline$[61][62][60][16][18][17][228][226][227][276][243][245][247][253][249][250][248][230][234][237][241]$ \\
{$[240][233][246][242][231][229][244][277][279][278][280][281][282][283][285][289][288][287][286]$} \\
{$[290][198][192][191][172][171][170][168][169][167][311][312][162][163][164][165][166]$} \\
\hline Route 8 \\
\hline 204][203][205][12][13][15][14][19][20][122][121][120][119][118][117][116][114][112][113][115][110][111] \\
\hline
\end{tabular}

The following Table 4 presents the economic order quantities, optimum reorder points, and optimum service levels of all retail stores placed in Route 1 based on the derived reordering inventory control policy obtained in this simulation case. 
Table 4. The economic order quantities (EOQ), optimal reorder points (ROP), and optimal service levels (SL) of all retail stores located in Route 1 based on POPIRPSDR.

\begin{tabular}{cccccccccccc}
\hline Node & EOQ & ROP & SL & Node & EOQ & ROP & SL & Node & EOQ & ROP & SL \\
\hline$[62]$ & 376 & 67 & 73.8 & {$[60]$} & 387 & 67 & 73.6 & {$[16]$} & 392 & 67 & 73.5 \\
{$[18]$} & 378 & 67 & 73.8 & {$[17]$} & 375 & 67 & 73.8 & {$[228]$} & 381 & 67 & 73.8 \\
{$[226]$} & 376 & 67 & 73.8 & {$[227]$} & 375 & 67 & 73.8 & {$[276]$} & 377 & 67 & 73.8 \\
{$[243]$} & 375 & 67 & 73.8 & {$[245]$} & 376 & 67 & 73.8 & {$[247]$} & 376 & 67 & 73.8 \\
{$[253]$} & 375 & 67 & 73.8 & {$[249]$} & 374 & 67 & 73.8 & {$[250]$} & 375 & 67 & 73.8 \\
{$[248]$} & 376 & 67 & 73.8 & {$[230]$} & 376 & 67 & 73.8 & {$[234]$} & 376 & 67 & 73.8 \\
{$[237]$} & 375 & 67 & 73.8 & {$[241]$} & 375 & 67 & 73.8 & {$[240]$} & 375 & 67 & 73.8 \\
{$[233]$} & 375 & 67 & 73.8 & {$[246]$} & 377 & 67 & 74.3 & {$[242]$} & 375 & 67 & 73.8 \\
{$[231]$} & 376 & 67 & 73.8 & {$[229]$} & 376 & 67 & 73.8 & {$[244]$} & 377 & 67 & 73.8 \\
{$[277]$} & {$[375]$} & 67 & 73.8 & {$[279]$} & 375 & 67 & 73.8 & {$[278]$} & 375 & 67 & 73.8 \\
{$[280]$} & 376 & 67 & 73.8 & {$[281]$} & 375 & 67 & 73.8 & {$[282]$} & 375 & 67 & 73.8 \\
{$[283]$} & 375 & 67 & 73.8 & {$[285]$} & 376 & 67 & 73.8 & {$[289]$} & 376 & 67 & 73.8 \\
{$[288]$} & 374 & 67 & 73.8 & {$[287]$} & 375 & 67 & 73.8 & {$[286]$} & 375 & 67 & 73.8 \\
{$[290]$} & 376 & 67 & 73.8 & {$[198]$} & 394 & 67 & 73.5 & {$[192]$} & 376 & 67 & 73.8 \\
{$[191]$} & 376 & 67 & 73.8 & {$[172]$} & 377 & 67 & 73.8 & {$[171]$} & 375 & 67 & 73.8 \\
{$[170]$} & 376 & 67 & 73.8 & {$[168]$} & 376 & 67 & 73.8 & {$[169]$} & 374 & 67 & 73.8 \\
{$[167]$} & 376 & 67 & 73.8 & {$[311]$} & 380 & 67 & 73.8 & {$[312]$} & 376 & 67 & 73.8 \\
{$[162]$} & 378 & 67 & 73.8 & {$[163]$} & 375 & 67 & 73.8 & {$[164]$} & 375 & 67 & 73.8 \\
{$[165]$} & 376 & 67 & 73.8 & {$[166]$} & 376 & 67 & 73.8 & & & & \\
\hline
\end{tabular}

By first conducting the IRPSDR model with the ROP mode, the reorder point method adopts precise control over each merchandise item in inventory at each retail store. Except the first replenishment and delivery run, most retail stores will definitely be delivered at different time schedules for the remaining replenishment and delivery runs. Therefore, it misses joint ordering, transporting, or buying economies. Alternatively, under periodic review control, inventory levels for multiple merchandise items and different retail stores can be reviewed at the same time so that these merchandise items may be ordered and delivered at the same time. Thus, this realizes production, transportation, or purchasing economies. Therefore, the IRPSDR model with the PR mode will be applied after the first delivery run for this simulation case. According to the results of Table 5, the total inventory routing cost for conducting the IRPSDR model with the PR mode by running the proposed repeated target heuristic method is 4,098,427 NT dollars, which is clearly higher than the lowest total inventory routing cost of 3,070,733 NT dollars obtained by the IRPSDR model with the ROP mode.

Table 5. The simulated numerical results for PRIRPSDR.

\begin{tabular}{ccccc}
\hline Savings & $\begin{array}{c}\text { Target Insert } \\
\text { Heuristic }\end{array}$ & $\begin{array}{c}\text { Target Exchange } \\
\text { Heuristic }\end{array}$ & $\begin{array}{c}\text { Repeated } \\
\text { Target }\end{array}$ \\
\hline Number of routes & 8 & 8 & 8 & 8 \\
Inventory cost & $2,055,086$ & $2,054,881$ & $2,054,725$ & $2,007,067$ \\
Shortage cost & $1,306,090$ & $1,306,133$ & $1,306,239$ & $1,277,459$ \\
Return cost & 220,773 & 220,800 & 220,808 & 216,284 \\
Safety cost & 86,239 & 86,262 & 86,262 & 84,292 \\
Transport cost & 151,369 & 151,073 & 150,783 & 144,287 \\
Order cost & 376,854 & 376,876 & 376,894 & 369,038 \\
Total cost & $4,196,411$ & $4,196,025$ & $4,195,711$ & $4,098,427$ \\
Total cost saving & $0 \%$ & $0.01 \%$ & $0.02 \%$ & $2.33 \%$ \\
\hline
\end{tabular}

Moreover, the modified route sequences, the optimal common review interval, and optimal maximum inventory levels of all retail stores placed in these designed routes will be obtained in the sequel in Tables 6 and 7. 
Table 6. The modified route order for retail stores delivered in the first route and the last route based on PRIRPSDR.

\begin{tabular}{c}
\hline Route 1 \\
\hline$[64][65][62][61][60][124][121][119][120][118][115][113][111][110][109][106][105][104][103]$ \\
{$[101][85][84][82][83][99][77][76][73][72][70][71][69][68][75][98][97][95][92][93]$} \\
{$[94][96][90][87][86][81][88][91][89][102][79][80][107][108][112][114][116][117]$} \\
\hline Route 8 \\
\hline$[63][192][197][1][7][2][3][66][15][299][295][386][384][385][228][17][18][16]$ \\
\hline
\end{tabular}

Table 7. The modified optimal maximum inventory level and optimal common review interval of all retail stores located in Route 1 based on PRIRPSDR.

\begin{tabular}{ccccccccccccccc}
\hline Node & $\mathbf{M}^{*}$ & $\mathbf{T}^{*}$ & Node & $\mathbf{M}^{*}$ & $\mathbf{T}^{*}$ & $\mathbf{N o d e}$ & $\mathbf{M}^{*}$ & $\mathbf{T}^{*}$ & $\mathbf{N o d e}$ & $\mathbf{M}^{*}$ & $\mathbf{T}^{*}$ & Node & $\mathbf{M}^{*}$ & $\mathbf{T}^{*}$ \\
\hline$[64]$ & 507 & 8.44 & {$[65]$} & 502 & 8.44 & {$[62]$} & 494 & 8.44 & {$[61]$} & 491 & 8.44 & {$[60]$} & 500 & 8.44 \\
{$[124]$} & 500 & 8.44 & {$[121]$} & 499 & 8.44 & {$[119]$} & 494 & 8.44 & {$[120]$} & 493 & 8.44 & {$[118]$} & 492 & 8.44 \\
{$[115]$} & 493 & 8.44 & {$[113]$} & 499 & 8.44 & {$[111]$} & 492 & 8.44 & {$[110]$} & 490 & 8.44 & {$[109]$} & 490 & 8.44 \\
{$[106]$} & 490 & 8.44 & {$[105]$} & 490 & 8.44 & {$[104]$} & 490 & 8.44 & {$[103]$} & 492 & 8.44 & {$[101]$} & 483 & 8.44 \\
{$[85]$} & 489 & 8.44 & {$[84]$} & 490 & 8.44 & {$[82]$} & 482 & 8.44 & {$[83]$} & 500 & 8.44 & {$[99]$} & 510 & 8.44 \\
{$[77]$} & 492 & 8.44 & {$[76]$} & 490 & 8.44 & {$[73]$} & 492 & 8.44 & {$[72]$} & 493 & 8.44 & {$[70]$} & 490 & 8.44 \\
{$[71]$} & 500 & 8.44 & {$[69]$} & 490 & 8.44 & {$[68]$} & 496 & 8.44 & {$[75]$} & 482 & 8.44 & {$[98]$} & 482 & 8.44 \\
{$[97]$} & 488 & 8.44 & {$[95]$} & 481 & 8.44 & {$[92]$} & 490 & 8.44 & {$[93]$} & 474 & 8.44 & {$[94]$} & 483 & 8.44 \\
{$[96]$} & 490 & 8.44 & {$[90]$} & 490 & 8.44 & {$[87]$} & 482 & 8.44 & {$[86]$} & 490 & 8.44 & {$[81]$} & 492 & 8.44 \\
{$[88]$} & 475 & 8.44 & {$[91]$} & 490 & 8.44 & {$[89]$} & 490 & 8.44 & {$[102]$} & 482 & 8.44 & {$[79]$} & 490 & 8.44 \\
{$[80]$} & 482 & 8.44 & {$[107]$} & 490 & 8.44 & {$[108]$} & 501 & 8.44 & {$[112]$} & 492 & 8.44 & {$[114]$} & 492 & 8.44 \\
{$[116]$} & 500 & 8.44 & & & & & & & & & & & & \\
\hline
\end{tabular}

\subsection{The Simulated Results for IRPSDRCO ${ }_{2}$ Model}

In this proposed simulation case, the IRPSDRCO 2 model with the ROP mode $\left(\mathrm{ROPIRPSDRCO}_{2}\right)$ will be applied in the first replenishment run to deliver products to all retail stores. For the remaining replenishment runs, the IRPSDRCO ${ }_{2}$ model with the PR mode $\left(\mathrm{PRIRPSDRCO}_{2}\right)$ will be conducted to deliver products to all retail stores.

First, the total inventory routing costs for the proposed ROPIRPSDRCO $\mathrm{O}_{2}$ based on the above default operating data and parameters by conducting the savings method, target insert heuristic method, target exchange heuristic method, and repeated target heuristic method are illustrated in Table 8.

Table 8. The simulated numerical results for ROPIRPSDRCO 2 .

\begin{tabular}{ccccc}
\hline Savings & $\begin{array}{c}\text { Target Insert } \\
\text { Heuristic }\end{array}$ & $\begin{array}{c}\text { Target Exchange } \\
\text { Heuristic }\end{array}$ & $\begin{array}{c}\text { Repeated } \\
\text { Target }\end{array}$ \\
\hline Number of routes & 8 & 8 & 8 & 8 \\
$\mathrm{CO}_{2}$ cost & 135,536 & 135,129 & 134,754 & 133,803 \\
Inventory cost & $1,511,421$ & $1,510,552$ & $1,510,122$ & $1,509,690$ \\
Shortage cost & 310,884 & 310,789 & 310,804 & 311,121 \\
Return cost & 381,108 & 381,002 & 380,999 & 381,259 \\
Safety cost & 97,059 & 97,082 & 97,082 & 97,120 \\
Transport cost & 196,365 & 196,214 & 196,115 & 195,890 \\
Order cost & 516,596 & 516,486 & 516,518 & 516,685 \\
Total cost & $3,148,969$ & $3,147,254$ & $3,146,394$ & $3,145,568$ \\
Total cost saving & $0 \%$ & $0.054 \%$ & $0.082 \%$ & $0.11 \%$ \\
\hline
\end{tabular}

With regard to Table 8 , the repeated target heuristic method obtained the lowest total inventory routing cost of 3,145,568 NT dollars. Due to the lowest total inventory routing cost coming from the IRPSDRCO ${ }_{2}$ model with ROP mode, it can then determine the optimum delivery routes, and economic 
order quantities, the optimum service levels, and the reorder points of all retail stores placed in these scheduled routes. From the perspective of decision making on this proposed inventory routing problem, the above result means that the decision makers should first deliver all products through eight planned optimal delivery routes to all retail stores, which carry out the related reordering inventory control policies. Table 9 displays the detailed route sequence for the first and last route of the eight planned delivery routes.

Table 9. The route order for retail stores delivered in Route 1 and 8 based on the ROPIRPSDRCO 2 .

\begin{tabular}{|c|}
\hline Route 1 \\
\hline $\begin{array}{c}{[64][65][58][57][56][54][55][5][198][196][197][193][194][195][192][191][172][171][170]} \\
{[169][168][167][311][314][318][328][327][325][326][343][344][342][341][340][339][338][321]} \\
{[336][324][329][330][331][332][334][335][333][348][347][346][317][316][315][313][312][162][163][165][166]}\end{array}$ \\
\hline Route 8 \\
\hline$[4][6][18][15][14][19][124][373][374][108][109][74][235][205][203][204]$ \\
\hline
\end{tabular}

Table 10 presents the optimum service levels, optimum reorder points, and economic order quantities of all retail stores placed in Route 1 based on the derived reordering inventory control policy obtained in this simulation case.

Table 10. The economic order quantities (EOQ), optimal reorder points (ROP), and optimal service levels (SL) of all retail stores located in Route 1 based on POPIRPSDRCO ${ }_{2}$.

\begin{tabular}{cccccccccccc}
\hline Node & EOQ & ROP & SL & Node & EOQ & ROP & SL & Node & EOQ & ROP & SL \\
\hline$[65]$ & 391 & 69 & 73 & {$[58]$} & 506 & 62 & 71.9 & {$[57]$} & 425 & 63 & 72.1 \\
{$[56]$} & 389 & 66 & 73 & {$[54]$} & 367 & 65 & 73.8 & {$[55]$} & 367 & 63 & 73 \\
{$[5]$} & 403 & 65 & 73.8 & {$[198]$} & 566 & 63 & 71.1 & {$[196]$} & 355 & 60 & 72.7 \\
{$[197]$} & 346 & 62 & 74.1 & {$[193]$} & 349 & 60 & 72.6 & {$[194]$} & 349 & 61 & 73.3 \\
{$[195]$} & 340 & 60 & 73.6 & {$[192]$} & 368 & 62 & 73.8 & {$[191]$} & 363 & 65 & 73.9 \\
{$[172]$} & 346 & 60 & 74.3 & {$[171]$} & 342 & 61 & 74.1 & {$[170]$} & 348 & 62 & 75 \\
{$[169]$} & 344 & 61 & 74.4 & {$[168]$} & 332 & 60 & 73.7 & {$[167]$} & 360 & 63 & 73.7 \\
{$[311]$} & 377 & 62 & 72.7 & {$[314]$} & 353 & 60 & 74.2 & {$[318]$} & 355 & 61 & 73.4 \\
{$[328]$} & 347 & 60 & 72.6 & {$[327]$} & 346 & 61 & 74.1 & {$[325]$} & 342 & 61 & 74.1 \\
{$[326]$} & 344 & 62 & 74.8 & {$[343]$} & 366 & 62 & 74.4 & {$[344]$} & 360 & 62 & 73.7 \\
{$[342]$} & 351 & 61 & 73.7 & {$[341]$} & 350 & 62 & 74.8 & {$[340]$} & 349 & 62 & 73.8 \\
{$[339]$} & 349 & 63 & 75 & {$[338]$} & 360 & 65 & 74.2 & {$[321]$} & 360 & 62 & 72.9 \\
{$[336]$} & 367 & 65 & 74 & {$[324]$} & 350 & 63 & 74.3 & {$[329]$} & 353 & 62 & 73.8 \\
{$[330]$} & 343 & 62 & 75.5 & {$[331]$} & 354 & 63 & 74.3 & {$[332]$} & 344 & 62 & 74.8 \\
{$[334]$} & 366 & 66 & 73.7 & {$[335]$} & 359 & 65 & 74.5 & {$[333]$} & 355 & 62 & 73.5 \\
{$[348]$} & 368 & 63 & 73.2 & {$[347]$} & 363 & 63 & 73.2 & {$[346]$} & 366 & 65 & 74.4 \\
{$[317]$} & 353 & 61 & 73.7 & {$[316]$} & 356 & 63 & 74.8 & {$[315]$} & 342 & 60 & 73.6 \\
{$[313]$} & 357 & 62 & 74.7 & {$[312]$} & 352 & 61 & 74.2 & {$[162]$} & 359 & 62 & 73.8 \\
{$[163]$} & 339 & 61 & 74.4 & {$[165]$} & 356 & 62 & 74.4 & {$[166]$} & 344 & 62 & 75.5 \\
\hline
\end{tabular}

By first conducting the IRPSDRCO ${ }_{2}$ model with the ROP mode, the reorder point method applies precise control over each merchandise item at an inventory level at each retail store. Except the first replenishment and delivery run, most retail stores will deliver at different time tables for the remaining replenishment and delivery runs, and, therefore, will miss joint ordering, transporting, or buying economies. Alternatively, under periodic review control, inventory levels for multiple merchandise items and different retail stores can be reviewed at the same time so that these merchandise items may be ordered and delivered at the same time, which will help achieve production, transportation, or purchasing economies. Accordingly, the IRPSDRCO 2 model with the PR mode will be conducted after the first delivery run for this simulated case. Regarding Table 11, the total inventory routing cost for implementing the IRPSDRCO ${ }_{2}$ model using the PR mode by running the proposed repeated 
target heuristic method is 4,098,427 NT dollars, which is clearly higher than the lowest total inventory routing cost of 3,145,568 NT dollars acquired by the IRPSDRCO ${ }_{2}$ model with the ROP mode.

Table 11. The simulated numerical results for PRIRPSDRCO $\mathrm{P}_{2}$

\begin{tabular}{ccccc}
\hline Savings & $\begin{array}{c}\text { Target Insert } \\
\text { Heuristic }\end{array}$ & $\begin{array}{c}\text { Target Exchange } \\
\text { Heuristic }\end{array}$ & $\begin{array}{c}\text { Repeated } \\
\text { Target }\end{array}$ \\
\hline Number of routes & 8 & 8 & 8 & 8 \\
$\mathrm{CO}_{2}$ cost & 88,827 & 86,693 & 85,640 & 84,502 \\
Inventory cost & $2,199,992$ & $2,198,978$ & $2,198,106$ & $2,197,282$ \\
Shortage cost & $1,440,289$ & $1,441,719$ & $1,442,036$ & $1,442,465$ \\
Return cost & 186,690 & 186,782 & 186,838 & 186,909 \\
Safety cost & 83,227 & 83,308 & 83,331 & 83,354 \\
Transport cost & 131,551 & 130,982 & 130,703 & 130,406 \\
Order cost & 352,635 & 352,801 & 352,889 & 352,999 \\
Total cost & $4,483,211$ & $4,481,263$ & $4,479,543$ & $4,477,917$ \\
Total cost saving & $0 \%$ & $0.045 \%$ & $0.082 \%$ & $0.12 \%$ \\
\hline
\end{tabular}

Furthermore, the modified route sequences, the optimal common review interval, and optimal maximum inventory levels of all retail stores located in these designed routes will be demonstrated in the sequel in Tables 12 and 13.

Table 12. The modified route order for retail stores delivered in the first route and the last route based on PRIRPSDRCO .

\section{Route 1.}

[64][65][63][62][61][60][59][47]][48][52][32][31][30][28][29][34][37][21]

[20][25][24][23][22][39][38][26][7][66][160][8][9][10][12][11][125][123][124][121]

[120][118][119][35][36][42][43][44][41][53][50][49][45][40][46][54][55][56][57][58]

\section{Route 8}

[373][375][372][374][371][132][133][127][377][416][412][413][414][415][392][368]

Table 13. The modified optimal maximum inventory level $\left(\mathrm{M}^{*}\right)$ and optimal common review interval

$\left(\mathrm{T}^{*}\right)$ of all retail stores located in Route 1 based on PRIRPSDRCO .

\begin{tabular}{ccccccccccccccc}
\hline Node & $\mathbf{M}^{*}$ & $\mathbf{T}^{*}$ & Node & $\mathbf{M}^{*}$ & $\mathbf{T}^{*}$ & $\mathbf{N o d e}$ & $\mathbf{M}^{*}$ & $\mathbf{T}^{*}$ & $\mathbf{N o d e}$ & $\mathbf{M}^{*}$ & $\mathbf{T}^{*}$ & Node & $\mathbf{M}^{*}$ & $\mathbf{T}^{*}$ \\
\hline$[64]$ & 592 & 9.81 & {$[64]$} & 577 & 9.81 & {$[65]$} & 585 & 9.81 & {$[63]$} & 574 & 9.81 & {$[62]$} & 563 & 9.81 \\
{$[61]$} & 560 & 9.81 & {$[60]$} & 553 & 9.81 & {$[59]$} & 574 & 9.81 & {$[47]$} & 574 & 9.81 & {$[48]$} & 554 & 9.81 \\
{$[52]$} & 572 & 9.81 & {$[32]$} & 564 & 9.81 & {$[31]$} & 573 & 9.81 & {$[30]$} & 564 & 9.81 & {$[28]$} & 553 & 9.81 \\
{$[29]$} & 564 & 9.81 & {$[34]$} & 573 & 9.81 & {$[37]$} & 563 & 9.81 & {$[21]$} & 563 & 9.81 & {$[20]$} & 573 & 9.81 \\
{$[25]$} & 563 & 9.81 & {$[24]$} & 564 & 9.81 & {$[23]$} & 563 & 9.81 & {$[22]$} & 564 & 9.81 & {$[39]$} & 575 & 9.81 \\
{$[38]$} & 564 & 9.81 & {$[26]$} & 563 & 9.81 & {$[7]$} & 631 & 9.81 & {$[66]$} & 573 & 9.81 & {$[160]$} & 563 & 9.81 \\
{$[8]$} & 563 & 9.81 & {$[9]$} & 563 & 9.81 & {$[10]$} & 582 & 9.81 & {$[12]$} & 563 & 9.81 & {$[11]$} & 573 & 9.81 \\
{$[125]$} & 565 & 9.81 & {$[123]$} & 571 & 9.81 & {$[124]$} & 571 & 9.81 & {$[121]$} & 563 & 9.81 & {$[120]$} & 562 & 9.81 \\
{$[118]$} & 570 & 9.81 & {$[119]$} & 563 & 9.81 & {$[35]$} & 563 & 9.81 & {$[36]$} & 563 & 9.81 & {$[42]$} & 574 & 9.81 \\
{$[43]$} & 564 & 9.81 & {$[44]$} & 563 & 9.81 & {$[41]$} & 563 & 9.81 & {$[53]$} & 565 & 9.81 & {$[50]$} & 575 & 9.81 \\
{$[49]$} & 573 & 9.81 & {$[45]$} & 563 & 9.81 & {$[40]$} & 574 & 9.81 & {$[46]$} & 553 & 9.81 & {$[54]$} & 563 & 9.81 \\
{$[55]$} & 565 & 9.81 & {$[56]$} & 553 & 9.81 & {$[57]$} & 562 & 9.81 & {$[58]$} & 563 & 9.81 & & & \\
\hline
\end{tabular}

4.3. The Sensitivity Analysis for Decision Making Based on Different Parameters of IRPSDRCO 2 with ROP Mode

The sensitivity analyses will be conducted for IRPSDRCO 2 with the ROP mode based on different parameters including truck loading capacity, inventory carrying cost percentage, unit shortage cost, unit returning cost, unit ordering cost, and unit transport cost to provide very helpful decision-making information for IRPSDRCO 2 system design. 


\subsubsection{The Sensitivity Analysis for Unit Shortage Cost Regarding ROPIRPSDRCO $\mathrm{C}_{2}$ Mode}

In Table 14, the sensitivity analysis of the proposed IRPSDRCO $\mathrm{C}_{2}$ model with the ROP mode is conducted by altering the value of unit shortage cost including 17, 20, and 30 NT dollars.

Table 14. The results of the sensitivity analysis for unit shortage cost regarding ROPIRPSDRCO ${ }_{2}$.

\begin{tabular}{cccc}
\hline Unit Shortage Cost & $\mathbf{1 7}(\mathbf{P} \mathbf{2})$ & $\mathbf{2 0} \mathbf{( P 1 )}$ & $\mathbf{3 0}(\mathbf{P 3})$ \\
\hline Avg. economical order quantity & 362.2806801002386 & 367.6611406491646 & 374.68872981622906 \\
Avg. customer service level & 0.685509937947494 & 0.7217077828162289 & 0.7882045131264915 \\
Avg. reorder point (ROP) & 60.76459955131267 & 62.88044453937948 & 67.0083066706444 \\
Shortage cost & $316,226.562783$ & $311,121.16557799996$ & $293,733.67545800004$ \\
Return cost & $347,851.076907$ & $381,259.38203000004$ & $458,331.295066$ \\
Transport cost & $197,534.92232199997$ & $195,889.508211$ & $189,015.98844500002$ \\
Order cost & $521,791.6705200001$ & $516,684.96149899997$ & $499,086.702821$ \\
CO cost & $134,235.507927$ & $133,803.528023$ & $128,520.77131899999$ \\
Inventory cost & $1,487,596.928634$ & $1,509,690.175717$ & $1,538,546.862447$ \\
Safety cost & $80,839.582928$ & $97,119.69595$ & $13,4081.850629999997$ \\
Total cost & $3,086,076.2520210003$ & $3,145,568.4170079995$ & $3,241,317.1461859997$ \\
\hline
\end{tabular}

According to Table 14, when the unit shortage cost is rising, it is shown to apply higher economical order quantity and follow the EOQ formula mechanism in Equation (12). It is cost-effective to conduct the optimal inventory control policy with a higher customer service level and ROP to avoid the stock-out situation.

The inventory cost is enlarged because of higher economical order quantity and the safety cost is increased due to a higher ROP level. Moreover, higher economical order quantity will lead to less delivery runs, and further cause lower transport cost, $\mathrm{CO}_{2}$ cost, and order cost. Although unit shortage cost is increased, higher economical order quantity will cause less delivery runs and further lead to lower shortage cost in these three specific numerical cases. The return cost is increased when unit shortage cost is increased in spite of the fact that higher economical order quantity will cause less delivery runs. The main reason is that the optimal inventory control policy of higher customer service level and higher reorder point will bring about more return products in these three given numerical cases.

\subsubsection{The Sensitivity Analysis for Unit Return Cost Regarding the ROPIRPSDRCO $\mathrm{M}_{2}$ Mode}

In Table 15, the sensitivity analysis of the proposed IRPSDRCO ${ }_{2}$ model with the ROP mode is conducted by changing the value of unit return cost including 2, 5, and 8 NT dollars.

Table 15. The results of the sensitivity analysis for unit return cost based on ROPIRPSDRCO 2 .

\begin{tabular}{cccc}
\hline Unit Return Cost & 2(P4) & $\mathbf{5 ( P 1 )}$ & $\mathbf{8 ~ ( P 5 ) ~}$ \\
\hline Avg. economical order quantity & 323.72524695942724 & 367.6611406491646 & 393.5172602076372 \\
Avg. customer service level & 0.8288953341288783 & 0.7217077828162289 & 0.6370330715990453 \\
Avg. reorder point (ROP) & 70.1427878711217 & 62.88044453937948 & 58.126808556085905 \\
Return cost & $242,343.15085300003$ & $381,259.38203$ & $442,927.24244199996$ \\
Shortage cost & $176,889.140344$ & $311,121.16557799996$ & $417,886.12161499995$ \\
Transport cost & $217,897.50238000002$ & $195,889.508211$ & $181,276.482837$ \\
Order cost & $586,727.5537360001$ & $516,684.96149899997$ & $477,061.964324$ \\
CO ${ }_{2}$ cost & $136,870.035103$ & $133,803.528023$ & $124,683.774746$ \\
Inventory cost & $1,329,280.609106$ & $1,509,690.175717$ & $1,615,860.573818$ \\
Safety cost & $156,735.17534600003$ & $97,119.69595$ & $60,234.35759999999$ \\
Total cost & $2,846,743.1668680003$ & $3,145,568.4170079995$ & $3,319,930.5173819996$ \\
\hline
\end{tabular}


In the light of Table 15, when the unit return cost is rising, it directly gives rise to higher economical order quantity derived by the EOQ formula in Equation (12). It is profitable to apply a lower customer service level and reorder point to prevent the returning good situation.

It is certain that the inventory cost is increased because of higher economical order quantity applied and the safety cost is decreased due to lower ROP level conducted. Furthermore, higher economical order quantity will cause less delivery runs, and even cause lower transport cost, $\mathrm{CO}_{2} \operatorname{cost}$, and order cost. Although unit return cost is increased, higher economical order quantity causes less delivery runs but still leads to higher shortage cost due to optimal inventory control policy of a lower customer service level.

Lastly, the return cost is increased as a result of increased unit shortage cost in spite of the fact that the optimal inventory control policy of a lower customer service level and lower reorder point will bring about less return products.

4.3.3. The Sensitivity Analysis for Inventory Carrying Cost Percentage Regarding ROPIRPSDRCO 2 Mode

In Table 16, the sensitivity analysis of the proposed IRPSDRCO ${ }_{2}$ model with the ROP mode is conducted by changing the value of inventory carrying cost percentage including $0.1,0.2$, and 0.3 NT dollars.

Table 16. The results of the sensitivity analysis for inventory carrying cost percentage based on ROPIRPSDRCO ${ }_{2}$.

\begin{tabular}{cccc}
\hline Inv. Carrying Cost Percentage & $\mathbf{0 . 1 ( P 6 )}$ & $\mathbf{0 . 2 ( P 1 )}$ & $\mathbf{0 . 3}(\mathbf{P 7 )}$ \\
\hline Avg. economical order quantity & 516.4508222792364 & 367.6611406491646 & 300.9720811789976 \\
Avg. customer service level & 0.7382509093078761 & 0.7217077828162289 & 0.706755417661098 \\
Avg. reorder point (ROP) & 63.828926723150346 & 62.88044453937948 & 62.024565682577574 \\
Return cost & $285,173.154945$ & $381,259.38203$ & $445,826.206703$ \\
Shortage cost & $199,926.216049$ & $311,121.16557799996$ & $409,594.383272$ \\
Transport cost & $137,782.33319099998$ & $195,889.508211$ & $239,284.056646$ \\
Order cost & $365,941.44981799996$ & $516,684.96149899997$ & $631,178.7617870001$ \\
CO Cost $_{\text {Inventory carrying cost }}$ & $91,389.16826900002$ & $133,803.528023$ & $163,406.76249$ \\
Safety cost & $1,060,325.1832150002$ & $1,509,690.175717$ & $1,853,777.3395060003$ \\
Total cost & $52,941.2821$ & $97,119.69595$ & $135,136.31348199997$ \\
& $2,193,478.787587$ & $3,145,568.4170079995$ & $3,878,203.8238860006$ \\
\hline
\end{tabular}

In line with Table 16, when the inventory carrying cost percentage is growing, it leads to increasing inventory carrying cost and small economical order quantity obtained by EOQ Equation (12). Therefore, tiny economical order quantity will cause more delivery runs, and further result in higher transport cost, order cost, and $\mathrm{CO}_{2}$ cost. It is also demonstrated that the proposed optimal inventory control policy adopts a low level of customer service and reorder point in order to refrain the high inventory carrying cost due to an increasing inventory carrying cost percentage. In addition, when the inventory carrying cost percentage is growing, more delivery runs, a low level of customer service, and reorder point will cause a higher shortage cost.

Table 16 also shows that the return cost is still increased even the growing inventory carrying cost percentage leads to the optimal inventory control policy, which implements the lower customer service level to reduce the amount of returning products. The main reason is that the increased effect of return cost caused by more delivery runs exceeds the decreased effect of return cost derived by the optimal inventory control policy to conduct a lower customer service level in these numerical cases. The safety inventory carrying cost is increased with a growing inventory carrying cost percentage because the increased effect of safety inventory carrying cost resulted in an increased inventory carrying cost percentage surpassing the decreased effect of safety inventory carrying cost incited by a smaller ROP. 


\subsubsection{The Sensitivity Analysis for Unit Order Cost Regarding ROPIRPSDRCO ${ }_{2}$ Mode}

In Table 17, the sensitivity analysis of the proposed IRPSDRCO ${ }_{2}$ model with the ROP mode is conducted by changing the value of the unit order cost including 50, 100, and 150 NT dollars.

Table 17. The results of the sensitivity analysis for order cost based on the ROPIRPSDRCO mode. $_{2}$

\begin{tabular}{cccc}
\hline Unit Order Cost & $\mathbf{5 0 ( P 8 )}$ & $\mathbf{1 0 0 ( P 1 )}$ & 150(P9) \\
\hline Avg. economical order quantity & 333.07674591646776 & 367.6611406491646 & 396.82105737470175 \\
Avg. customer service level & 0.7271167589498806 & 0.7217077828162289 & 0.7150125465393795 \\
Avg. reorder point (ROP) & 63.211571463007154 & 62.88044453937948 & 62.46793897374702 \\
Return cost & $427,872.793884$ & $381,259.38203$ & $346,273.37768599996$ \\
Shortage cost & $294,246.2735569999$ & $311,121.16557799996$ & $409,594.383272$ \\
Transport cost & $180,317.50740100004$ & $195,889.508211$ & $239,284.056646$ \\
Order cost & $712,785.0647349999$ & $516,684.96149899997$ & $631,178.7617870001$ \\
CO cost & $135,667.30414300002$ & $133,803.528023$ & $123,234.433798$ \\
Inventory carrying cost & $1,367,679.7340809996$ & $1,509,690.175717$ & $1,629,426.625762$ \\
Safety cost & $94,712.03499900002$ & $97,119.69595$ & $135,136.31348199997$ \\
Total cost & $2,863,149.467988999$ & $3,145,568.4170079995$ & $3,380,995.317938$ \\
\hline
\end{tabular}

With regard to Table 17, when the unit order cost is increasing, it directly leads to large economical order quantity derived by the EOQ formula in Equation (12) and further creates raising inventory carrying cost. A larger economical order quantity will cause less delivery runs and lower return cost and $\mathrm{CO}_{2}$ cost. It is also demonstrated that, in these three specific numerical cases, the proposed optimal inventory control policy adopts a low level of customer service and reorder point in order to refrain the high inventory carrying cost due to large economical order quantity. Moreover, the shortage cost is increased because the increased effect of shortage cost resulted in a low level of customer service and the reorder point surpasses the decreased effect of shortage cost created by fewer delivery runs.

\subsubsection{The Sensitivity Analysis for Variable Transport Cost Regarding ROPIRPSDRCO $\mathrm{Mode}$}

In Table 18, the sensitivity analysis of the proposed IRPSDRCO $\mathrm{C}_{2}$ model with the ROP mode is conducted by changing the value of variable transport cost comprising 3, 3.9, and 6 NT dollars.

Table 18. The results of the sensitivity analysis for transport cost based on the ROPIRPSDRCO mode. $^{2}$

\begin{tabular}{cccc}
\hline Variable Transport Cost & 3(P10) & 3.9(P1) & 6(P11) \\
\hline Avg. economical order quantity & 367.47435698329355 & 367.6611406491646 & 368.1022101718377 \\
Avg. customer service level & 0.7216928520286395 & 0.7217077828162289 & 0.7217892673031024 \\
Avg. reorder point (ROP) & 62.877638374701675 & 62.88044453937948 & 62.88886301909309 \\
Return cost & $381,502.65893700003$ & $381,259.38203$ & $380,589.360189$ \\
Shortage cost & $311,395.117129$ & $311,121.16557799996$ & $310,456.58468699997$ \\
Transport cost & $187,789.22743000003$ & $195,889.508211$ & $211,771.829377$ \\
Order cost & $517,020.288753$ & $516,684.96149899997$ & $515,636.49505400006$ \\
CO cost & $136,685.077666$ & $133,803.528023$ & $123,360.923431$ \\
Inventory carrying cost & $1,508,923.20467$ & $1,509,690.175717$ & $1,511,501.295426$ \\
Safety cost & $97,096.650637$ & $97,119.69595$ & $97,156.59510899999$ \\
Total cost & $3,140,412.2252219995$ & $3,145,568.4170079995$ & $3,150,473.083273$ \\
\hline
\end{tabular}

In Table 18, when the variable transport cost is enhancing, it undoubtedly derives bigger economical order quantity obtained by the EOQ Equation (12) and generates raising inventory carrying cost. A bigger economical order quantity will result in few delivery runs and still bring about less order cost and $\mathrm{CO}_{2}$ cost. 
It is also illustrated that the recommended optimal inventory control policies in these three specific numerical cases adopt an increasing level of customer service and reorder point, which certainly causes more safety cost. Moreover, the shortage cost is decreased because of less delivery runs and an increasing level of customer service and reorder point.

In these three specific numerical examples, the transport cost is increased because the increased effect of transport cost created by increased variable transport cost exceeds the declined effect of transport cost caused by fewer delivery runs. The return cost is decreased because the dropping influence of return cost made by fewer delivery runs transcends the consequence of more return products aroused by an increasing level of customer service and reorder point.

\subsubsection{The Sensitivity Analysis for Unit $\mathrm{CO}_{2}$ Cost Regarding ROPIRPSDRCO $\mathrm{C}_{2}$ Mode}

In Table 19, the sensitivity analysis of the proposed IRPSDRCO ${ }_{2}$ model with ROP mode is carried out by modifying the value of unit $\mathrm{CO}_{2}$ cost consisting of 35,40 , and 50 NT dollars.

Table 19. The results of the sensitivity analysis for unit $\mathrm{CO}_{2}$ cost based on ROPIRPSDRCO 2 .

\begin{tabular}{cccc}
\hline Unit CO2 Cost & 35(P12) & 40(P1) & 50(P13) \\
\hline Avg. economical order quantity & 338.9989540095465 & 367.6611406491646 & 369.46747189260134 \\
Avg. customer service level & 0.7878244272076373 & 0.7217077828162289 & 0.7215739785202864 \\
Avg. reorder point (ROP) & 67.02794975178999 & 62.88044453937948 & 62.87763837708832 \\
Return cost & $303,473.011349$ & $381,259.38203$ & $379,176.219548$ \\
Shortage cost & $224,964.25171699995$ & $311,121.16557799996$ & $309,714.503781$ \\
Transport cost & $210,786.64215400003$ & $195,889.508211$ & $191,901.28864600003$ \\
Order cost & $557,137.820401$ & $516,684.96149899997$ & $513,981.8406170001$ \\
CO cost & $125,101.491412$ & $133,803.528023$ & $153,883.81790300002$ \\
Inventory carrying cost & $1,391,997.5049579998$ & $1,509,690.175717$ & $1,517,107.3330760002$ \\
Safety cost & $132,283.16781799993$ & $97,119.69595$ & $97,064.41386099998$ \\
Total cost & $2,945,743.889809$ & $3,145,568.4170079995$ & $3,162,829.4174320004$ \\
\hline
\end{tabular}

According to the above results in Table 19, while the unit CO2 cost is growing, it spurs great economical order quantity acquired by the EOQ Equation (12) and generates rising inventory carrying cost. Moreover, great economical order quantity will lead to few delivery runs and give rise to less transport cost and order cost.

The suggested optimal inventory control policies in the above three specific numerical examples apply a decreasing level of customer service and reorder point, which cause less safety cost.

In the above three specific numerical cases, the $\mathrm{CO}_{2}$ cost is increasing. The increasing effect of $\mathrm{CO}_{2}$ cost generated by a growing unit $\mathrm{CO}_{2}$ cost outpaces the declining effect of $\mathrm{CO}_{2}$ cost caused by fewer delivery runs. On the contrary, the conflicting effect between fewer delivery runs and a decreasing level of customer level and reorder point leads to unclear ascending or descending trend of shortage cost.

\subsubsection{The Sensitivity Analysis for Truck Loading Capacity Regarding ROPIRPSDRCO $\mathrm{O}_{2}$ Mode}

In Table 20, the sensitivity analysis of the proposed IRPSDRCO $\mathrm{C}_{2}$ model with ROP mode is carried out based on three different truck loading capacity given by a 3.5-ton truck, a 7.8-ton truck, and an 11-ton truck. 
Table 20. The results of the sensitivity analysis for truck loading capacity regarding ROPIRPSDRCO ${ }_{2}^{1,2}$.

\begin{tabular}{cccc}
\hline & 3.5-Ton Truck & 7.8-Ton Truck & 11-Ton Truck \\
\hline Capacity (unit) & 3000 & 6686 & 9429 \\
Amortized cost & $133,272(8$ trucks $)$ & $66,636(4$ trucks $)$ & $49,977(3$ trucks $)$ \\
FCdis & 0.12315 & 0.1381 & 0.1667 \\
CO2-kg/Km & 0.3362 & 0.3770 & 0.4551 \\
ROPIRSDRCO2 & Total (CO2)(Trans) & Total $(\mathrm{CO})($ Trans $)$ & Total (CO2)(Trans) \\
Default & $\mathrm{P} 1: 3278840(133803)(329161)$ & $\mathrm{P} 14: 3229546(\mathbf{1 2 9 9 7 3})(\mathbf{1 9 4 3 8 1})$ & $\mathrm{P} 15: 3231619(138085)(246157)$ \\
$h_{s}=10$ & $\mathrm{P} 2: 033734(\mathbf{1 2 8 4 2 5})(336147)$ & $\mathrm{P} 16: 2999629(130059)(269624)$ & $\mathrm{P} 17: 3004747(141594)(\mathbf{2 5 5 4 7 3})$ \\
$h_{s}=30$ & $\mathrm{P} 3: 3374589(\mathbf{1 2 8 5 2 0})(322287)$ & $\mathrm{P} 18: 3362208(132900)(257270)$ & $\mathrm{P} 19: 3354400(134725)(\mathbf{2 4 0 9 0 5})$ \\
$h_{c}=2$ & $\mathrm{P} 4: 2980015(\mathbf{1 3 6 8 7 0})(351169)$ & $\mathrm{P} 20: 2949607(142247)(285476)$ & $\mathrm{P} 21: 2959038(160208)(\mathbf{2 7 2 0 4 4})$ \\
$h_{c}=8$ & $\mathrm{P} 5: 3453202(\mathbf{1 2 4 6 8 3})(314548)$ & $\mathrm{P} 22: 3419843(125016)(247795)$ & $\mathrm{P} 23: 3445381(136421)(\mathbf{2 3 4 6 4 5})$ \\
$\mathrm{I}=0.1$ & $\mathrm{P} 6: 2326750(91389)(271054)$ & $\mathrm{P} 24: 2281317(\mathbf{9 1 3 2 0})(204283)$ & $\mathrm{P} 25: 2277033(96982)(\mathbf{1 8 8 8 1 0})$ \\
$\mathrm{I}=0.3$ & $\mathrm{P} 25: \mathbf{2 2 7 7 0 3 3}(96982)(\mathbf{1 8 8 8 1 0})$ & $\mathrm{P} 26: 3957234(\mathbf{1 5 2 9 4 2})(302615)$ & $\mathrm{P} 27: 3972712(168780)(\mathbf{2 8 9 6 0 3})$ \\
$\mathrm{O}=50$ & $\mathrm{P} 8: 2996421(\mathbf{1 3 5 6 6 7})(313589)$ & $\mathrm{P} 28: 2962147(138182)(279812)$ & $\mathrm{P} 29: 2980792(162592)(\mathbf{2 6 8 0 2 7})$ \\
$\mathrm{O}=150$ & $\mathrm{P} 9: 3514267(123234)(372556)$ & $\mathrm{P} 30: 3466405(\mathbf{1 1 5 1 2 7})(244861)$ & $\mathrm{P} 31: 3502865(139163)(\mathbf{2 3 4 3 5 6})$ \\
$V t c=3$ & $\mathrm{P} 10: 3273684(\mathbf{1 3 6 6 8 5})(321061)$ & $\mathrm{P} 32: 3231181(137535)(254051)$ & $\mathrm{P} 33: 3172785(139280)(\mathbf{1 8 7 5 7 3})$ \\
$V t c=6$ & $\mathrm{P} 11: 3283745(\mathbf{1 2 3 3 6 0})(345043)$ & $\mathrm{P} 34: 3256044(127536)(279790)$ & $\mathrm{P} 35: 3271759(147664)(\mathbf{2 7 0 3 5 1})$ \\
$\mathrm{CO}_{2}=35$ & $\mathrm{P} 12: 3079015(125101)(344058)$ & $\mathrm{P} 36: 3223365(\mathbf{1 2 1 2 0 5})(263862)$ & $\mathrm{P} 37: 3232180(128619)(\mathbf{2 4 9 5 3 6})$ \\
$\mathrm{CO}_{2}=50$ & $\mathrm{P} 13: 3296101(\mathbf{1 5 3 8 8 3})(325173)$ & $\mathrm{P} 38: 3263371(154395)(258463)$ & $\mathrm{P} 39: 3284276(181867)(\mathbf{2 4 6 1 8 2})$ \\
\hline
\end{tabular}

${ }^{1}$ The total costs for different trucks include the total inventory routing costs and the amortized costs. ${ }^{2}$ The total transport costs for different trucks include the transport costs and the amortized costs.

Regarding the above results of Table 20, on the basis of total cost, it is designed to choose a 7.8-ton truck for 9 of 13 simulated cases, 11-ton truck for 3 of 13 simulated cases, and a 3.5-ton truck for only 1 of 13 simulated cases to conduct the routing delivery operation. However, only considering $\mathrm{CO}_{2}$ cost, it is optimized to apply a small-sized 3.5-ton truck for 8 of 13 simulated cases, middle size 7.8-ton truck for 5 of 13 simulated cases, and large size 11-ton truck for a none simulated case to do the routing delivery operation. Lastly, based on total transport cost, it is optimal to adopt the a large-sized 11-ton truck for 12 of 13 simulated cases, a middle-sized 7.8-ton truck for only one simulated case, and a small-sized 3.5-ton truck for a none simulated case to implement the routing delivery operation in the distribution system.

Conclusively, a 3.5-ton truck is more appropriate to be used in this proposed ROPIRPSDRCO 2 distribution system for considering $\mathrm{CO}_{2}$ cost. A 7.8-ton truck is more suitable to be adopted in this proposed ROPIRPSDRCO ${ }_{2}$ distribution system based on the total cost. An 11-ton truck is advisable to be employed in this proposed ROPIRPSDRCO ${ }_{2}$ distribution system concerning the total transport cost.

\subsection{The Performance Comparison of the Proposed Repeated Target Heuristic Method Regarding the ROPIRPSDRCO ${ }_{2}$ Mode}

In Table 21, the proposed repeated target heuristic method is compared with the savings method, the target insert heuristic method, the target exchange heuristic method based on the total inventory routing cost, and the CPU running time for all 39 simulation problems shown previously in Table 20.

According to the above outcomes in Table 21, it is clear that the lowest inventory routing costs are obtained by a repeated target heuristic method for all 39 simulated numerical cases. The average total inventory-routing cost calculated by the proposed repeated target heuristic method is 2,890,110, which saves $8 \%$ cost from the savings method. The average CPU running time obtained from the proposed repeated target heuristic method for all 39 simulated numerical cases is 5589 milliseconds, which adds $30.25 \%$ CPU time from the savings method. Although 30.25\% more CPU running time only counts for $8 \%$ cost saving for conducting a repeated target heuristic method, it is still cost-efficient because the CPU running time is 5589 milliseconds on average. 
Table 21. The performance of the inventory routing cost and CPU running time for a savings method, a target insert heuristic method, a target exchange heuristic method, and a repeated target heuristic method concerning ROPIRPSDRCO ${ }_{2}{ }^{3}$.

\begin{tabular}{|c|c|c|c|c|}
\hline & Savings & Target Insert Heuristic & $\begin{array}{c}\text { Target Exchange } \\
\text { Heuristic }\end{array}$ & Repeated Target \\
\hline P1 & $3,148,969(4327 \mathrm{~ms})$ & $3,147,254(4353 \mathrm{~ms})$ & 3,146,394(4411 ms) & $\mathbf{3 , 1 4 5 , 5 6 8}(5519 \mathrm{~ms})$ \\
\hline P2 & 2,913,670(4222 ms) & $2,911,607(4254 \mathrm{~ms})$ & $2,902,890(4316 \mathrm{~ms})$ & $2,900,462(6331 \mathrm{~ms})$ \\
\hline P3 & $3,275,300(4292 \mathrm{~ms})$ & $3,273,419(4318 \mathrm{~ms})$ & $3,246,676(4681 \mathrm{~ms})$ & $\mathbf{3}, \mathbf{2 4 1}, \mathbf{3 1 7}(5924 \mathrm{~ms})$ \\
\hline $\mathrm{P} 4$ & $2,851,743(4253 \mathrm{~ms})$ & $2,849,545(4279 \mathrm{~ms})$ & $2,849,423(4335 \mathrm{~ms})$ & $2,846,743(6169 \mathrm{~ms})$ \\
\hline P5 & $3,348,393(4356 \mathrm{~ms})$ & $3,346,570(4383 \mathrm{~ms})$ & $3,337,333(4447 \mathrm{~ms})$ & $3, \mathbf{3 1 9}, \mathbf{9 3 0}(5907 \mathrm{~ms})$ \\
\hline P6 & $2,203,284(4250 \mathrm{~ms})$ & 2,202,033(4281 ms) & $2,200,451(4328 \mathrm{~ms})$ & $\mathbf{2 , 1 9 3 , 4 7 8 ( 5 7 8 4 \mathrm { ms } )}$ \\
\hline P7 & $3,882,347(4252 \mathrm{~ms})$ & $3,880,249(4268 \mathrm{~ms})$ & $3,879,197(4346 \mathrm{~ms})$ & $\mathbf{3 , 8 7 8 , 2 0 3}(5955 \mathrm{~ms})$ \\
\hline P8 & $2,864,682(4440 \mathrm{~ms})$ & $2,864,375(4467 \mathrm{~ms})$ & $2,864,082(4524 \mathrm{~ms})$ & $2,863,149(5668 \mathrm{~ms})$ \\
\hline P9 & $3,393,315(4681 \mathrm{~ms})$ & $3,390,721(4708 \mathrm{~ms})$ & $3,385,946(4896 \mathrm{~ms})$ & $3,380,995(6372 \mathrm{~ms})$ \\
\hline P10 & $3,142,817(4429 \mathrm{~ms})$ & $3,141,340(4457 \mathrm{~ms})$ & $3,141,010(4516 \mathrm{~ms})$ & $\mathbf{3 , 1 4 0 , 4 1 2}(5682 \mathrm{~ms})$ \\
\hline P11 & $3,157,044(4206 \mathrm{~ms})$ & $3,153,807(4237 \mathrm{~ms})$ & $3,152,000(4315 \mathrm{~ms})$ & $\mathbf{3 , 1 5 0 , 4 7 3 ( 5 7 8 6 \mathrm { ms } )}$ \\
\hline P12 & $2,959,047(4379 \mathrm{~ms})$ & $2,950,308(4642 \mathrm{~ms})$ & 2,949,987(4701 ms) & $2,945,743(5535 \mathrm{~ms})$ \\
\hline P13 & $3,168,768(4322 \mathrm{~ms})$ & 3,165,393(4385 ms) & $3,163,375(4463 \mathrm{~ms})$ & $\mathbf{3 , 1 6 2 , 8 2 9}(6058 \mathrm{~ms})$ \\
\hline P14 & $3,177,124(4891 \mathrm{~ms})$ & $3,167,384(5048 \mathrm{~ms})$ & $3,166,384(5080 \mathrm{~ms})$ & $\mathbf{3 , 1 6 2 , 9 1 0}(5788 \mathrm{~ms})$ \\
\hline P15 & $3,202,542(4333 \mathrm{~ms})$ & $3,197,999(4357 \mathrm{~ms})$ & $3,185,368(4382 \mathrm{~ms})$ & $\mathbf{3 , 1 8 1 , 6 4 2}(5115 \mathrm{~ms})$ \\
\hline P16 & $2,953,995(4487 \mathrm{~ms})$ & $2,949,962(4512 \mathrm{~ms})$ & $2,948,759(4542 \mathrm{~ms})$ & $2,932,993(5367 \mathrm{~ms})$ \\
\hline P17 & $2,979,700(4342 \mathrm{~ms})$ & $2,975,182(4381 \mathrm{~ms})$ & $2,973,952(4409 \mathrm{~ms})$ & $2,954,770(5471 \mathrm{~ms})$ \\
\hline P18 & $3,304,118(4310 \mathrm{~ms})$ & $3,299,143(4335 \mathrm{~ms})$ & $3,298,737(4382 \mathrm{~ms})$ & $\mathbf{3}, \mathbf{2 9 5 , 5 7 2}(5397 \mathrm{~ms})$ \\
\hline P19 & $3,324,781(4322 \mathrm{~ms})$ & $3,320,280(4345 \mathrm{~ms})$ & $3,307,381(4370 \mathrm{~ms})$ & $\mathbf{3}, \mathbf{3 0 4}, \mathbf{4 2 3}(5078 \mathrm{~ms})$ \\
\hline P20 & $2,891,324(4270 \mathrm{~ms})$ & $2,889,395(4297 \mathrm{~ms})$ & $2,886,710(4327 \mathrm{~ms})$ & $\mathbf{2 , 8 8 2 , 9 7 1 ( 5 2 9 3 \mathrm { ms } )}$ \\
\hline P21 & $2,922,429(4293 \mathrm{~ms})$ & $2,922,429(4330 \mathrm{~ms})$ & $2,920,468(4355 \mathrm{~ms})$ & $2,909,061(5117 \mathrm{~ms})$ \\
\hline P22 & $3,373,933(4338 \mathrm{~ms})$ & $3,369,049(4364 \mathrm{~ms})$ & $3,368,406(4394 \mathrm{~ms})$ & $3,353,207(5703 \mathrm{~ms})$ \\
\hline P23 & $3,403,302(4387 \mathrm{~ms})$ & $3,398,228(4423 \mathrm{~ms})$ & $3,398,101(4450 \mathrm{~ms})$ & $3,395,404(5226 \mathrm{~ms})$ \\
\hline P24 & $2,224,284(4637 \mathrm{~ms})$ & $2,217,446(4782 \mathrm{~ms})$ & $2,216,736(4812 \mathrm{~ms})$ & $\mathbf{2 , 2 1 4 , 6 8 1 ( 5 7 4 1 \mathrm { ms } )}$ \\
\hline P25 & $2,241,284(4319 \mathrm{~ms})$ & $2,238,061(4344 \mathrm{~ms})$ & $2,229,177(4368 \mathrm{~ms})$ & $2,227,056(5301 \mathrm{~ms})$ \\
\hline P26 & $3,915,414(4657 \mathrm{~ms})$ & $3,910,578(4684 \mathrm{~ms})$ & $3,908,551(4714 \mathrm{~ms})$ & $3,890,598(5683 \mathrm{~ms})$ \\
\hline P27 & $3,947,878(4656 \mathrm{~ms})$ & $3,942,331(4691 \mathrm{~ms})$ & $3,926,807(4716 \mathrm{~ms})$ & $\mathbf{2 , 8 9 5 , 5 1 1}(5859 \mathrm{~ms})$ \\
\hline P28 & $2,906,278(4532 \mathrm{~ms})$ & $2,902,006(4578 \mathrm{~ms})$ & $2,901,631(4608 \mathrm{~ms})$ & $\mathbf{2 , 8 9 5 , 5 1 1}(5859 \mathrm{~ms})$ \\
\hline P29 & $2,943,009(4315 \mathrm{~ms})$ & $2,943,009(4339 \mathrm{~ms})$ & $2,931,918(4370 \mathrm{~ms})$ & $2,930,815(5144 \mathrm{~ms})$ \\
\hline P30 & $3,422,718(4342 \mathrm{~ms})$ & $3,418,829(4368 \mathrm{~ms})$ & $3,406,365(4398 \mathrm{~ms})$ & $3,399,769(4805 \mathrm{~ms})$ \\
\hline P31 & $3,456,899(4367 \mathrm{~ms})$ & $3,453,935(4391 \mathrm{~ms})$ & $3,453,539(4418 \mathrm{~ms})$ & $\mathbf{3}, \mathbf{4 5 2 , 8 8 8}(5911 \mathrm{~ms})$ \\
\hline P32 & $3,171,669(4871 \mathrm{~ms})$ & $3,167,903(4896 \mathrm{~ms})$ & $3,167,613(4941 \mathrm{~ms})$ & $\mathbf{3 , 1 6 4 , 5 4 5}(5843 \mathrm{~ms})$ \\
\hline P33 & $3,193,155(4319 \mathrm{~ms})$ & $3,188,760(4343 \mathrm{~ms})$ & $3,176,315(4369 \mathrm{~ms})$ & $\mathbf{3 , 1 7 2 , 7 8 5}(5191 \mathrm{~ms})$ \\
\hline P34 & $3,199,260(4394 \mathrm{~ms})$ & $3,194,847(4419 \mathrm{~ms})$ & $3,193,819(4450 \mathrm{~ms})$ & $\mathbf{3 , 1 8 9 , 4 0 8 ( 5 2 7 5 \mathrm { ms } )}$ \\
\hline P35 & $3,234,841(4311 \mathrm{~ms})$ & $3,234,841(4335 \mathrm{~ms})$ & $3,222,888(4359 \mathrm{~ms})$ & $3,221,782(5874 \mathrm{~ms})$ \\
\hline P36 & $3,163,848(4375 \mathrm{~ms})$ & $3,160,196(4400 \mathrm{~ms})$ & $3,159,673(4445 \mathrm{~ms})$ & $3,156,729(5376 \mathrm{~ms})$ \\
\hline P37 & $3,189,839(4481 \mathrm{~ms})$ & $3,184,920(4522 \mathrm{~ms})$ & $3,184,796(4547 \mathrm{~ms})$ & $\mathbf{3 , 1 8 2 , 2 0 3}(5254 \mathrm{~ms})$ \\
\hline P38 & 3,203,293(4399 ms) & $3,198,780(4423 \mathrm{~ms})$ & $3,198,400(4454 \mathrm{~ms})$ & $\mathbf{3 , 1 9 6 , 7 3 5 ( 5 7 4 8 \mathrm { ms } )}$ \\
\hline P39 & $3,247,553(4281 \mathrm{~ms})$ & $3,247,553(4304 \mathrm{~ms})$ & $3,235,457(4328 \mathrm{~ms})$ & $3,234,299(5080 \mathrm{~ms})$ \\
\hline \multirow[t]{3}{*}{ Avg. } & $3,141,124(4291 \mathrm{~ms})$ & $3,137,684(4442 \mathrm{~ms})$ & 3,132,993(4494 ms) & 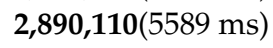 \\
\hline & Avg. cost saving rate & (Avg. CPU time adding rate) & & \\
\hline & $0 \%(0 \%)$ & $0.11 \%(3.52 \%)$ & $0.26 \%(4.73 \%)$ & $8 \%(30.25 \%)$ \\
\hline
\end{tabular}

Besides the above good comparison outcomes compared with our other proposed approaches, this research also compares our proposed repeated target heuristic method with four other combination methods including the heuristic-GA method, the heuristic-immune-GA method, heuristic-Tabu-1 method, and the heuristic-Tabu-2. Table 22 shows that the proposed repeated target heuristic method still has the best performance except the heuristic-Tabu-2 method in all 10 simulation cases including one VRP case and nine IRP cases. 
Table 22. The performance comparison regarding the total distance of the VRP simulated case and the inventory-routing cost of nine IRP simulated cases for Heuristic-GA, Heuristic-Immune-GA, Heuristic-Tabu-1, Heuristic-Tabu-2, and the repeated target heuristic method ${ }^{4}$.

\begin{tabular}{|c|c|c|c|c|c|}
\hline & Heuristic-GA & Heuristic-I-GA & Heuristic-Tabu-1 & Heuristic-Tabu-2 & $\begin{array}{c}\text { Repeated } \\
\text { Target }\end{array}$ \\
\hline Problem & $\begin{array}{l}\text { The inventory- } \\
\text { routing cost }\end{array}$ & (Running time) & & & \\
\hline VRP & 1111 & 1091 & 1150 & 976 & 910 \\
\hline IRP-Original & $2,440,439(765 \mathrm{~s})$ & $2,434,098(1346 s)$ & $2,401,122(530 \mathrm{~s})$ & $1,913,294(2044 \mathrm{~s})$ & $2,367,419(5.166 \mathrm{~s})$ \\
\hline IRP-Truck7.8 & $2,451,912(661 \mathrm{~s})$ & $2,446,016(1876 \mathrm{~s})$ & $2,469,810(516 s)$ & $2,228,069(1257 \mathrm{~s})$ & $2,391,207(4.956 \mathrm{~s})$ \\
\hline IRP-Truck11 & $2,442,376(759 \mathrm{~s})$ & $2,439,354(1290 \mathrm{~s})$ & $2,384,031(499 \mathrm{~s})$ & $2,142,576(1370 \mathrm{~s})$ & $2,399,745(4.401 \mathrm{~s})$ \\
\hline IRP-Inv0.1 & $1,675,662(672 \mathrm{~s})$ & $1,667,796(1243 \mathrm{~s})$ & $1,523,114(496 \mathrm{~s})$ & $1,274,173(1781 s)$ & $1,633,431(5.084)$ \\
\hline IRP-Inv0.3 & $3,055,485(761 \mathrm{~s})$ & $3,049,806(1484 \mathrm{~s})$ & $3,018,803(511 \mathrm{~s})$ & $2,637,720(2475 s)$ & $2,948,701(5.316 \mathrm{~s})$ \\
\hline IRP-Short10 & $2,398,256(683 s)$ & $2,380,918(1206 s)$ & $2,337,938(474 \mathrm{~s})$ & $1,608,643(1760 \mathrm{~s})$ & $2,260,029(5.713 \mathrm{~s})$ \\
\hline IRP-Short30 & $2,486,209(680 \mathrm{~s})$ & $2,471,670(1122 \mathrm{~s})$ & $2,447,865(431 \mathrm{~s})$ & $2,196,929(1845 s)$ & $2,401,703(5.920 \mathrm{~s})$ \\
\hline IRP-Order50 & $2,138,022(685 \mathrm{~s})$ & $2,131,091(1233 \mathrm{~s})$ & $2,013,402(479 s)$ & $1,795,523(2348 \mathrm{~s})$ & $1,978,929(5.045 \mathrm{~s})$ \\
\hline IRP-Order150 & $2,786,540(681 \mathrm{~s})$ & $2,778,875(1144 \mathrm{~s})$ & $2,752,236(493 \mathrm{~s})$ & $2,092,721(2276 \mathrm{~s})$ & $2,651,963(5.833 \mathrm{~s})$ \\
\hline Avg. (IRP) & $2,430,545(705 s)$ & $2,422,180(1327 \mathrm{~s})$ & $2,373,411(492 s)$ & $1,987,739(1906 s)$ & $2,337,014(5.27 \mathrm{~s})$ \\
\hline
\end{tabular}

${ }^{4}$ The CPU running time for the above nine simulated cases are calculated with unit of second.

According to the above simulated results in Table 22, it can be clearly shown that the performance of the proposed repeated target heuristic method is greatly superior to the Heuristic-GA combination method, Heuristic-Immune-GA combination method, and Heuristic-Tabu-1 combination method for both the inventory routing cost and CPU running time. However, the average inventory routing cost for conducting a repeated target heuristic method is 2,337,014, which is poorer than the Heuristic-Tabu-2 combination method for which the inventory routing cost is $1,987,739$. Although a repeated target heuristic method counts for $17.57 \%$ more inventory routing cost compared to the Heuristic-Tabu-2 combination method, it is still an advantage because that average CPU running time is only $5.27 \mathrm{~s}$ when compared to a Heuristic-Tabu-2 combination method with averagely 12,266 s of CPU running time. Accordingly, the superior performance of the repeated target heuristic method in CPU running time takes effort to be able to respond instantly in this proposed online distribution system.

\section{Conclusions}

This research first develops the structure of the proposed online distribution system, which integrates a mobile device, Internet of vehicle, and Google Map to enhance the online IRPSDRCO related navigation system for the distribution center operated by a specific logistics firm. The main structure is described in Figure 1 including (1) IRPSDR and IRPSDRCO ${ }_{2}$ mathematical model, (2) online IRPSDR and IRPSDRCO ${ }_{2}$ distribution system, (3) online in-vehicle navigation system, and (4) Google Map navigated vehicles associated with GPS devices, mobile devices, IoT sensors, Google Map Apps.

The proposed ROPIRPSDR, PRIRPSDR, ROPIRPSDRCO ${ }_{2}$, and PRIRPSDRCO $\mathrm{P}_{2}$ mathematical models are developed to find the total inventory routing cost, the $\mathrm{CO}_{2}$ emission cost, the optimal delivery routes, the economic order quantities, the optimal reordering points, the optimal service levels, the optimal common review interval, and the optimal maximum inventory levels for all retail stores delivered in these proposed routes. In the first phase, this research applied the savings method to obtain the initial solution. In the second phase, a target insert heuristic method, a target exchange heuristic method, and a repeated target heuristic method are further conducted to improve the initial solution to achieve the optimal solution and the related scheduled routing planning for four ROPIRPSDR, PRIRPSDR, ROPIRPSDRCO ${ }_{2}$, and PRIRPSDRCO ${ }_{2}$ simulated cases. In practice, ROPIRPSDR and ROPIRPSDRCO ${ }_{2}$ model should be applied for the first replenishment and delivery run, which carry out the related reordering inventory control policies to adopt very precise control over each merchandise item in the inventory level. PRIRPSDR and the PRIRPSDRCO ${ }_{2}$ model with a periodic review inventory 
policy should be conducted for the remaining replenishment and delivery runs in this proposed vehicle navigation system.

The sensitivity analyses are further conducted for the proposed ROPIRPSDRCO $\mathrm{O}_{2}$ model based on different parameters including unit shortage cost, unit return cost, inventory carrying cost percentage, unit ordering cost, unit transport cost, and truck loading capacity to provide very helpful decision-making information for ROPIRPSDRCO ${ }_{2}$ distribution system design.

Specifically, the sensitivity simulation results based on different logistics parameters can help decision makers to choose the appropriate type of truck to deliver products to all convenient stores located in the planned optimal delivery routes depending on total inventory routing cost, total $\mathrm{CO}_{2}$ cost, and total transport cost. It can be concluded that a 3.5-ton truck is more appropriate to be used in this proposed ROPIRPSDRCO $\mathrm{C}_{2}$ distribution system for concerning $\mathrm{CO}_{2}$ cost. A 7.8-ton truck is more suitable to be adopted in this proposed ROPIRPSDRCO $\mathrm{O}_{2}$ distribution system based on total inventory routing cost. An 11-ton truck is advisable to be employed in this proposed ROPIRPSDRCO 2 distribution system considering total transport cost.

The performance of the proposed Repeated target heuristic method is compared with the savings method, target insert heuristic method, target exchange heuristic method proposed by this study, and four other combination methods including Heuristic-GA method, Heuristic-Immune-GA method, Heuristic-Tabu-1 method, and Heuristic-Tabu-2. Accordingly, the performance of the proposed repeated target heuristic method regarding the inventory routing cost is better than all other methods except the Heuristic-Tabu-2 combination method. Furthermore, the superior performance of the repeated target heuristic method in CPU running time takes plenty of advantage being able to respond instantly in this proposed online distribution system.

Consequently, from the point of view of theoretic implication and breakthrough, this study first considers the cost derived from returning out-of-date products back to depot to modify the typical IRP problem into Inventory-routing problem with simultaneous deliveries and returns (IRPSDR) to design the related distribution system. Due to the enhanced environmental regard concerned by the whole world, this study designs the online distribution system to include the produced $\mathrm{CO}_{2}$ emission cost into the objective function of the IRPSDR model and become the IRPSDRCO model, $^{2}$ which includes ROPIRPSDR, PRIRPSDR, ROPIRPSDRCO ${ }_{2}$, and PRIRPSDRCO ${ }_{2}$. From the point of view of management implication of this study, it should be very helpful for logistics firms to design their distribution system by following the structure and the detailed procedure flow of the online distribution system described in Figures 1 and 2. Lastly, the research limitation of this study is that assuming the travel time between two retail stores is fixed depends on the actual distance between these two stores without considering the traffic situation. In the future, the real traffic travel time between two retail stores will also be considered in this proposed IRPSDRCO $\mathrm{C}_{2}$ model.

Author Contributions: Conceptualization, G.-S.L.; Data curation, G.-S.L.; Formal analysis, G.-S.L.; Methodology, G.-S.L.; Software, G.-S.L.; Writing—original draft, G.-S.L.; Writing—review \& editing, G.-S.L. and K.-P.L. All authors have read and agreed to the published version of the manuscript.

Funding: This research received no external funding.

Conflicts of Interest: The authors declare no conflict of interest.

\section{References}

1. Abdelmaguid, T.F.; Dessouky, M.M. A genetic algorithm approach to the Integrated Inventory-distribution problem. Int. J. Prod. Res. 2006, 44, 4445-4461. [CrossRef]

2. Agra, A.; Christiansen, M.; Delgado, A.; Simonetti, L. Hybrid heuristics for a short sea inventory routing problem. Eur. J. Oper. Res. 2014, 236, 924-935. [CrossRef]

3. Zhang, C.; Nemhauser, G.; Sokol, J.; Cheon, M.-S.; Keha, A. Flexible solutions to maritime inventory routing problems with delivery time windows. Comput. Oper. Res. 2018, 89, 153-162. [CrossRef]

4. Liu, G.S.; Lin, K.P. A Decision Support System of Green Inventory-Routing Problem. Ind. Manag. Data Syst. 2019, 119, 89-110. [CrossRef] 
5. Cordeau, J.-F.; Laganà, D.; Musmanno, R.; Vocaturo, F. A decomposition-based heuristic for the multiple-product inventory-routing problem. Comput. Oper. Res. 2015, 55, 153-166. [CrossRef]

6. Coelho, L.C.; Laporte, G. Improved solutions for inventory-routing problems through valid inequalities and input ordering. Int. J. Prod. Econ. 2014, 155, 391-397. [CrossRef]

7. Galina, I.; Sabine, L.; Fouad, R. The inventory-routing problem of returnable transport items with time windows and simultaneous pickup and delivery in closed-loop supply chains. Int. J. Prod. Econ. 2017, 183, 570-582.

8. Singh, J.; Anix, J.; Saravanan, M. Inventory Routing and Pricing Problem in a Supply Chain Network Design by a Heuristic Method. Appl. Math. Inf. Sci. 2017, 11, 465-470. [CrossRef]

9. Vansteenwegen, P.; Mateo, M. An iterated local search algorithm for the single-vehicle cyclic inventory routing problem. Eur. J. Oper. Res. 2014, 237, 802-813. [CrossRef]

10. Langley, C.J., Jr.; Coyle, J.J.; Gibson, B.J.; Novack, R.A.; Bardi, E.J. Managing Supply Chains-A Logistics Approach, 8th ed.; South-Western Cengage Learning: Boston, MA, USA, 2008.

11. Mirzapour Al-e-hashem, S.M.J.; Rekik, Y. Multi-product multi-period Inventory Routing Problem with a transshipment option: A green approach. Int. J. Prod. Econ. 2014, 57, 80-88. [CrossRef]

12. Ministry of Transportation and Communication. Transport Policy Report-Green Transport; Ministry of Transportation and Communication: Taipei, Taiwan, 2012.

13. Tseng, P.-H.; Lin, D.-Y.; Chien, S. Investigating the impact of highway electronic toll collection to the external cost: A case study in Taiwan. Technol. Forecast. Soc. Chang. 2014, 86, 265-272. [CrossRef]

14. Soysal, M.; Bloemhof-Ruwaard, J.M.; Haijema, R.; van der Vorst, J.G.A.J. Modeling an Inventory Routing Problem for perishable products with environment considerations and demand uncertainty. Int. J. Prod. Econ. 2015, 164, 118-133. [CrossRef]

15. Soysal, M.; Bloemhof-Ruwaard, J.M.; Haijema, R.; van der Vorst, J.G.A.J. Modeling a green inventory routing problem for perishable products with horizontal collaboration. Comput. Oper. Res. 2018, 89, 168-182. [CrossRef]

16. Osman, I.H. Metastrategy simulated annealing and tabu search algorithms for the vehicle routing problem. Ann. Oper. Res. 1993, 41, 421-451. [CrossRef]

17. Gupta, D.K. Tabu search for vehicle routing problems (VRPs). Int. J. Comput. Math. 2002, 79, $693-701$. [CrossRef]

18. Irnicha, S.; Laganàb, D.; Schlebuschc, C.; Vocaturo, F. Two-phase branch-and-cut for the mixed capacitated general routing problem. Eur. J. Oper. Res. 2015, 243, 17-29. [CrossRef]

19. Koc, C.; Karaoglan, I. The green vehicle routing problem: A heuristic based exact solution approach. Appl. Soft Comput. 2016, 39, 154-164. [CrossRef]

20. Montoya, A.; Guéret, C.; Mendoza, J.E.; Villegas, J.G. A multi-space sampling heuristic for the green vehicle routing problem. Transp. Res. Part C 2015, in press. [CrossRef]

21. Norouzi, N.; Sadegh-Amalnick, M.; Alinaghiyan, M. Evaluating of the particle swarm optimization in a periodic vehicle routing problem. Measurement 2015, 62, 162-169. [CrossRef]

22. Tiwari, A.; Chang, P.-C. A block recombination approach to solve green vehicle routing problem. Int. J. Prod. Econ. 2015, 164, 379-387. [CrossRef]

23. Chen, Y.M.; Lin, C.T. A coordinated approach to hedge the risks in stochastic inventory-routing problem. Comput. Ind. Eng. 2009, 56, 1095-1112. [CrossRef]

24. Zhang, Y.Q.; Mingyao, M.L.; Liu, E. Hybrid metaheuristic solutions to inventory location routing problem. Transp. Res. Part E 2014, 70, 305-323. [CrossRef]

25. Tuzun, D.; Burke, L.I. A two-phase tabu search approach to the location routing problem. Eur. J. Oper. Res. 1999, 116, 87-99. [CrossRef]

26. Clark, G.; Wright, J.W. Scheduling of vehicles from a central depot to a number of delivery points. Oper. Res. 1964, 2, 568-581. [CrossRef]

27. Lin, S. Computer solutions of the TSP. Bell Syst. Tech. J. 1965, 44, 2245-2269. [CrossRef]

28. Srivastava, R. Alternate solution procedures for the location-routing problem. Omega Int. J. Manag. Sci. 1993, 21, 497-506. [CrossRef] 
29. Liu, S.C.; Lin, C.C. A heuristic method for the combined location routing and inventory problem. Int. J. Adv. Manuf. Technol. 2005, 26, 372-381. [CrossRef]

30. Liu, S.C.; Lee, S.B. A two-phase heuristic method for the multi-depot location routing problem taking inventory control decisions into consideration. Int. J. Adv. Manuf. Technol. 2003, 22, 941-950. [CrossRef]

(C) 2020 by the authors. Licensee MDPI, Basel, Switzerland. This article is an open access article distributed under the terms and conditions of the Creative Commons Attribution (CC BY) license (http://creativecommons.org/licenses/by/4.0/). 